\title{
ACURÁCIA DE MAPAS ALTIMÉTRICOS OBTIDOS COM DGPS NA COLHEITA DE CEREAIS
}

\section{LUIZ CLAUDIO MOREIRA CREMONINI}

\author{
Dissertação apresentada à Escola Superior \\ de Agricultura "Luiz de Queiroz", \\ Universidade de São Paulo, para obtenção \\ do título de mestre em Agronomia, Área de \\ Concentração: Máquinas Agrícolas.
}

\section{PIRACICABA}

\section{Estado de São Paulo - Brasil}

Dezembro - 2002 


\title{
ACURÁCIA DE MAPAS ALTIMÉTRICOS OBTIDOS COM DGPS NA COLHEITA DE CEREAIS
}

\section{LUIZ CLAUDIO MOREIRA CREMONINI}

\author{
Engenheiro Agrônomo
}

Orientador: Prof. Dr. JOSÉ PAULO MOLIN

Dissertação apresentada à Escola Superior de Agricultura "Luiz de Queiroz", Universidade de São Paulo, para obtenção do título de mestre em Agronomia, Área de Concentração: Máquinas Agrícolas.

\author{
PIRACICABA \\ Estado de São Paulo - Brasil \\ Dezembro - 2002
}


Dados Internacionais de Catalogação na Publicação (CIP)

DIVISÃO DE BIBLIOTECA E DOCUMENTAÇÃO - ESALQ/USP

\author{
Cremonini, Luiz Claudio Moreira \\ Ac urácia de mapas a ltimétric os obtidos com DGPS na colheita de cereais \\ / Luiz Claudio Moreira Cremonini. - - Piracicaba, 2002. \\ 61 p. : il. \\ Dissertação (mestrado) - - Escola Superior de Agricultura Luiz de Queiroz, \\ 2002. \\ Bibliografia. \\ 1. Agric ultura de precisão 2. Altimetria 3. Cerea is (produtivida de) 4. \\ Geoproc essamento 5. Monitoramento 6. Simulação (estatística) 7. Tec nologi. \\ agríc ola I. Título
}

CDD 631.3

"Permitida a cópia total ou parcial deste documento, desde que citada a fonte - $\mathrm{O}$ autor" 


\section{DEDICATÓRIA}

A meu Pai, pelo apoio e amor dedicados durante toda vida.

As minhas tias Ermínia e Alayde, que me incentivaram e me apoiaram durante a toda minha jornada estudantil e pessoal.

Ainda à meus mentores Edson Cremonini e Henrique Luiz Varesio que incentivaram o caminho por mim trilhado e ainda o futuro que está por vir. 


\section{AGRADECIMENTOS}

A Deus, pela possibilidade de criarmos um mundo melhor.

Ao Prof. Dr. José Paulo Molin pela oportunidade concedida e pela orientação neste trabalho.

Aos Professores do Curso de Máquinas Agrícolas.

Aos funcionários do Departamento de Engenharia Rural.

A Jesuíno Ferrari no auxilio de trabalhos de campo.

A Andrés E. Lai Reyes e ao Prof. Dr. Hilton Thadeu Z. do Couto do CIAGRI-USP pelo empréstimo de GPS e apoio para obtenção de dados.

Ao amigo Juliano C.G. Leal pela convivência durante a realização do curso e ao apoio de trabalhos de Campo. E a todos meus amigos pela convivência e paciência durante a realização do meu curso.

A todos os colegas de curso pelo período de convivência.

Aos estagiários do g-MAP (Grupo de Mecanização e Agricultura de Precisão) pelo companheirismo e pela oportunidade de crescimento pessoal e profissional.

Aos funcionários do Setor Agrícola da Universidade de São Paulo campus de Pirassununga pela auxilio de trabalhos de Campo e convivência.

A empresa Santiago \& Cintra pelo empréstimo de GPS para a realização deste trabalho.

A empresa John Deere do Brasil pelo apoio na obtenção de dados de campo. 


\section{SUMÁRIO}

Página

LISTA DE FIGURAS....................................................................................... vii

LISTA DE TABELAS …............................................................................ ix

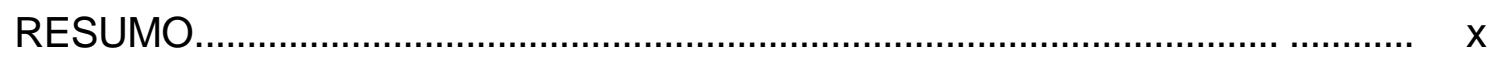

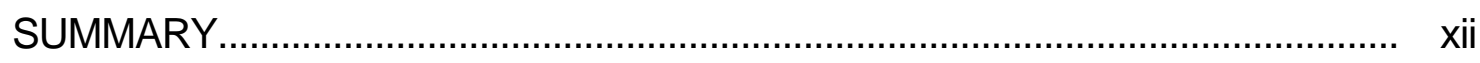

1 INTRODUÇÃO

2 REVISÃO DE LITERATURA ................................................................. 3

2.1 Agricultura de Precisão e sistemas de posicionamento ............................ 3

2.2 Altimetria em Agricultura de Precisão .................................................... 7

2.3 Geração de mapas altimétricos via DGPS ............................................... 11

3 MATERIAL E MÉTODOS........................................................................ 15

3.1 Avaliação da acurácia do posicionamento vertical de dois receptores de

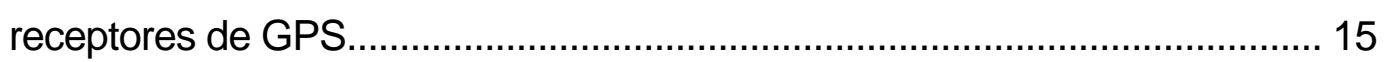

3.2 Obtenção de mapas altimétricos via DGPS em simulações de colheitas de cereais............................................................................... 20

3.3 Mapas altimétricos obtidos com monitor de produtividade....................... 23

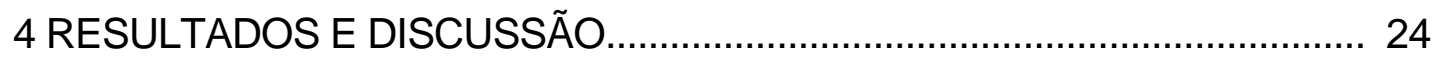

4.1 Acurácia do posicionamento vertical de dois receptores de GPS .......... 24

4.2 Acurácia de mapas altimétricos via DGPS obtidos através de simulação de colheita de cereais ........................................................ 28 
4.3 Acurácia de mapas altimétricos obtidos com monitor de produtividade .................................................................................. 42

4.4 Considerações gerais ................................................................ 50

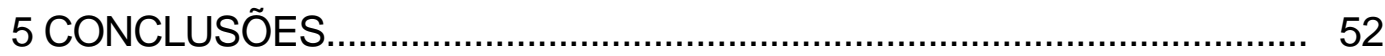

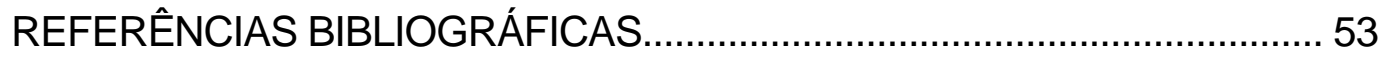




\section{LISTA DE FIGURAS}

Página

1 Obtenção de dados para reprodução dos perfis com a utilização de mira e nível.

2 Receptores de GPS utilizados para a obtenção dos dados; à esquerda receptor Ag 114 e palm top para armazenamento dos dados; à direita receptor PRO XR e coletor de dados TDC 1

3 Trator utilizado na obtenção dos dados e antenas dos receptores de GPS sobre a capota do trator.

4 Representação gráfica da freqüência acumulada do erro em módulo, para o receptor de GPS 1, nas três velocidades de deslocamento.

5 Representação gráfica da freqüência acumulada do erro em módulo, para o receptor de GPS 2, nas três velocidades de deslocamento

6 Freqüência acumulada do erro em módulo para os dois perfis como media das três velocidades de deslocamento para cada receptor de GPS

7 Área agrícola de 6,9 ha, mostrando os pontos onde foram coletados os dados para o levantamento topográfico convencional com o uso de uma estação total.

8 Modelo de elevação do terreno obtido pelo método convencional e interpolação dos dados por krigagem.

9 Freqüência acumulada do módulo do erro para as três simulações de operação de colheita, obtidas pelo critério de comparação por células...... 32

10 Freqüência acumulada do módulo do erro para as três simulações de operação de colheita, obtidas pelo critério de comparação pelo raio de 
11 Freqüências acumuladas das junções de dados das simulações de operação de colheita, pelo critério de comparação por células

12 Freqüências acumuladas dos erros em módulo para os dados de altimetria para as junções de dados das simulações de colheitas, critério de comparação por raio de busca.

13 Reprodução do modelo de elevação do terreno com dados da primeira simulação de colheita pelo critério de comparação por células.

14 Reprodução do modelo de elevação do terreno com dados da primeira simulação de colheita pelo critério de comparação por raio de busca....... 41

15 Representação gráfica da freqüência acumulada dos erros, obtidos pelo critério de comparação por células, com dados provenientes de monitor de produtividade

16 Representação gráfica da freqüência acumulada dos erros, obtidos pelo critério de comparação por raio de busca, com dados provenientes de monitor de produtividade.

17 Reprodução de modelos de elevação do terreno, a partir de dados do monitoramento da colheita 1 , com erros obtidos pelo critério de comparação por raio de busca. 


\section{LISTA DE TABELAS}

Página

1 Resultados da análise estatística descritiva dos erros de altitude dos dados obtidos com os receptores de GPS, avaliados em dois perfis, em relação aos dados do levantamento realizado pelo método topográfico.........................................................................................

2 Resultados da análise estatística descritiva dos erros de altitude, obtidos pelo receptor de GPS em simulações de colheitas de cereais, em relação aos dados do levantamento realizado pelo método convencional

3 Resultados da análise estatística descritiva dos erros de altitude, obtidos através do monitoramento das colheitas 1 e 2 , em relação aos dados do levantamento realizado pelo método convencional. 


\title{
Acurácia de mapas altimétricos obtidos com DGPS na colheita de cereais
}

\author{
Autor: LUIZ CLÁUDIO MOREIRA CREMONINI \\ Orientador: Prof. Dr. JOSÉ PAULO MOLIN
}

\section{RESUMO}

A produção agrícola passa por grandes transformações perante um mercado sempre mais competitivo e com consumidores mais exigentes, tendo que se obter maiores produtividades com menor uso de insumos e defensivos agrícolas. Diante deste cenário, novas formas de gerenciamento agrícola se fazem necessárias e com técnicas de Agricultura de Precisão se torna possível compreender e intervir em algumas variáveis de produção agrícola. Na região centro-sul brasileira uma das características marcantes é a topografia nem sempre favorável à agricultura mecanizada. O relevo, por sua vez, pode influenciar vários fatores de produção como gênese, textura, retenção de água e teores de nutrientes do solo, severidade de doença, entre outros. No mapeamento da produtividade, etapa essencial na obtenção de informações para se implementar o ciclo de Agricultura de Precisão, são coletadas diversas informações, entre elas a altitude dos pontos amostrados no terreno. Este trabalho teve como objetivo avaliar a acurácia de mapas altimétricos obtidos por receptores de GPS. A execução se deu em três etapas, a primeira avaliando a acurácia de posicionamento vertical de dois receptores de GPS, um 
com correção de sinal por pós-processamento e outro através de sinal via satélite em tempo real. A segunda etapa avaliou a acurácia de mapas altimétricos gerados com dados de simulações de colheitas de cereais, comparando-os com levantamento realizado por método convencional e a terceira etapa avaliou a acurácia de mapas altimétricos obtidos por sistema comercial de monitoramento de produção obtido em duas colheitas seguidas nessa mesma área. A correção pós-processada do sinal de GPS se mostrou mais acurada que a correção via satélite e os mapas altimétricos obtidos nas simulações de colheita e nas colheitas reais oferecem qualidade mínima necessária para a obtenção de informação de altimetria, para regiões de relevo mais acidentado, porém não aplicável para regiões com relevos planos. A junção dos dados de diferentes passadas, tanto nas simulações quanto nas colheitas reais melhorou a qualidade da informação de altimetria obtida com DGPS. 


\title{
Accuracy of elevation maps generated with DGPS with on yield monitors
}

\author{
Author: LUIZ CLAUDIO MOREIRA CREMONINI \\ Adviser: Prof. Dr. JOSÉ PAULO MOLIN
}

\section{SUMMARY}

A agricultural has been exposed to strong transformations, with a market always more competitive and with more exigent consumers and farmers having to obtain larger yields with less use of agricultural defensives. With this scenery, new forms of agricultural management are necessary and the use of precision agriculture techniques, is a possibility on trying to understand and interfere on production factors. In the southern Brazilian region the rough topography, is an important caracteristic not always favorable to mechanized agriculture. Topography can correlated with production factors, like genesis, texture, water

and nutrients content in the soil, severity of diseases, among others. In the yield mapping process, first step of precision agriculture, altitude data is collected together with several other data. This work aims to evaluate the accuracy of elevation maps generated with GPS receivers. It was conducted on three stages. First, the accuracy of vertical position was evalauted on two GPS 
receivers, one with differential correction on post processing and other with real time differential correction by satelite. The second stage, evaluated the accuracy of elevation maps generated by simulation of harvesting operation and the third stage evaluated the accuracy of elevation maps generated with datas from a commercial yield mapping system generated on two harvesting seasons on the same area. The post processing differential correction showed to be more acurate than the real time differential correction. The elevation maps generated with simulated and real harvesting operations offered a minimum quality for altitude data, for regions with uneven surface but not for flat regions. Joining altitude data from different simulations on consecutive real harvesting operation improved the quality of altitude information obtained with DGPS. 


\section{INTRODUÇÃO}

A partir da geração de mapas de produtividade, é possível constatar a variabilidade espacial da produção em áreas agrícolas, evidenciando-se que uma área não é homogênea, o que leva a produtividades distintas, e, por conseqüência a rentabilidade econômica variável. A atividade de produção agrícola exige grande eficiência perante um mercado sempre mais competitivo. Sendo assim, torna-se necessária a obtenção de maiores produtividades com menor uso de insumos e de defensivos agrícolas. Com o emprego de práticas de agricultura de precisão, torna-se possível realizar tratamentos diferenciados em áreas onde há variabilidade espacial, racionalizando-se o uso de insumos e de defensivos agrícolas e, com isso, gerando-se menor impacto sobre o ambiente.

As causas da variabilidade podem ser as mais diversas, por isso, a geração confiável de informação, relacionada às causas ou aos seus efeitos, torna-se uma ferramenta de grande importância para a tomada de decisões. Com a disponibilização do GPS (Sistema de Posicionamento Global) para uso civil, seu emprego na agricultura vem sendo cada vez mais freqüente, o que permite a obtenção de diversas informações que podem auxiliar no aumento da eficácia em operações agrícolas e da qualidade do gerenciamento do sistema de produção nas culturas agrícolas.

Especialmente nas regiões agrícolas do centro sul brasileiro, o relevo das áreas agrícolas é acidentado. A variação altimétrica encontrada pode estar 
correlacionada a diversos fatores de produção agrícola, tais como gênese, textura, retenção de água e teores de nutrientes no solo, ocorrência de doenças, dentre outros, causando, assim, influências na produtividade em uma mesma área. Detectar e manejar áreas distintas dentro de um mesmo talhão faz-se necessário, para extrair-se o máximo da potencialidade da área e manejar de forma racional suas limitações para a produção agrícola.

Nesse contexto, este trabalho foi desenvolvido objetivando mensurar a acurácia de mapas altimétricos, gerados com DGPS e empregados em operações agrícolas, especialmente na colheita de cereais com monitor de produtividade, para que se tenha domínio do potencial e das limitações dessa informação. 


\section{REVISÃO DE LITERATURA}

\subsection{Agricultura de Precisão e Sistemas de Posicionamento}

A Agricultura de Precisão é um conjunto de técnicas que propõem o tratamento localizado dos pontos do terreno com base na variabilidade espacial, procurando maximizar $o$ uso da terra e dos insumos, aumentando a produtividade da propriedade e diminuindo o custo com defensivos agrícolas (Molin, 1998).

A Agricultura de Precisão contém três componentes primários: o GPS (Sistema de Posicionamento Global), que fornece a posição, sistemas para a aplicação de insumos com taxas variadas e um banco de dados que fornece a informação necessária para desenvolver as relações de causa e efeito e as respostas à aplicação de insumos a várias condições especificamente localizadas (Cambardella \& Karlen,1999, citado por Menegatti 2002). De acordo com Molin \& Ruiz (1999), o crescimento da Agricultura de Precisão deve-se à viabilização e àpopularização do uso de GPS, uma ferramenta fundamental.

Buick \& Callaghan (1997) salientam que com a utilização de GPS, elevase o grau de gerenciamento das propriedades agrícolas. Dessa forma é possível obterem-se informações importantes para o manejo de áreas, visando ao uso racional dos insumos e das operações agrícolas. A obtenção de dados de altitude, através de receptores de GPS, auxilia nessa função, podendo 
balizar a tomada de decisões, já que busca melhor compreensão sobre a influência da altitude nos fatores de produção.

Em estudo conduzido por Robert (2002), onde foram pesquisados 108 trabalhos realizados para avaliar a viabilidade econômica da adoção de técnicas de Agricultura de Precisão, 63\% apresentaram resultados positivos para adoção de técnicas de Agricultura de Precisão; 26\% mostraram resultados mistos e $11 \%$, resultados negativos. Esses resultados evidenciam o potencial de uso de técnicas de Agricultura de Precisão para um sistema de produção agrícola mais sustentável e, possivelmente, mais rentável.

A posição de um determinado ponto pode ser calculada a partir das distâncias e dos ângulos existentes entre este e outros dois ou mais pontos cujas coordenadas sejam conhecidas (Stafford \& Ambler, 1994). Para a determinação da posição de um dado local, hoje é possível utilizarem-se modernos sistemas de posicionamento. Dentre eles, o mais difundido e em pleno funcionamento é o GPS. O sistema de posicionamento GPS começou a ser desenvolvido em 1973 pelo Departamento de Defesa dos Estados Unidos, como fruto da corrida armamentista contra a ex-União Soviética (Blitzkow, 1995). De acordo com Han et al. (1995), a formação do sistema GPS, em sua versão final, consiste em 24 satélites, dos quais 21 ativos e 3 de reserva, com órbita conhecida e a uma altitude de 20200 quilômetros.

O sistema GPS é normalmente divido em três segmentos: espacial, de controle e usuário. O segmento espacial é composto pela constelação de 24 satélites, distribuídos em seis órbitas de 60․ O sistema de controle consiste em uma estação de controle situada em Colorado Springs, nos EUA, de estações de monitoramento e de antenas para a retransmissão do sinal para a estaçãomestre, distribuídas ao redor do mundo. O segmento usuário consiste nos 
diversos modelos de receptores de GPS com acurácias e preços variáveis (Morgan \& Ess, 1997; Lechner \& Baumann, 2000).

A acurácia dos receptores de GPS esta ligada à freqüência de recebimento dos sinais dos satélites. Há basicamente três tipos de receptores: aqueles que sintonizam a fase portadora $L 1$, os que utilizam a fase $L 2$ e ainda os que recebem sinais das fases $L 1$ e $L 2$. O posicionamento dado para a fase portadora L1, de 1575,42 MHz, utiliza o código C/A para o cálculo da posição e é realizado em função da distância entre o receptor e o satélite. A acurácia está ligada ao bom arranjamento dos satélites visados, o qual, por sua vez, depende de eles estarem bem distribuídos de horizonte a horizonte. Neste sentido, satélites muito próximos afetam a acurácia do posicionamento e estão sujeitos a erros pela deflexão do sinal na troposfera e na ionosfera. O posicionamento dado através da fase portadora $\mathrm{L} 2$, de $1227,60 \mathrm{MHz}$, produz-se pela diferença de fase entre o sinal de referência gerado pelo oscilador do receptor (código $P$ ) e o sinal recebido do satélite. A acurácia dos receptores que utilizam este método é melhor em relação aqueles que utilizam o código C/A. (Lamparelli et al., 2001; Hofmann et al., 1992; Logsdon, 1992).

De acordo com Baio et al. (1998), a acurácia do sistema GPS depende de vários fatores, como a configuração da constelação dos satélites visados no momento do posicionamento, a freqüência do sinal utilizado para o posicionamento (L1, L2) a configuração do receptor e o método utilizado para a correção diferencial (satélite, rádio, pós-processado).

De acordo com Molin (2001), além do sistema GPS, há ainda o sistema GLONASS, desenvolvido pela ex União Soviética, hoje operado pela Rússia. É semelhante ao GPS, com constelação de 24 satélites. Atualmente, o sistema passa por dificuldades operacionais, devido ao número reduzido de satélites em operação. No mercado, há receptores que podem receber sinais tanto desse 
sistema como do GPS. A comunidade Européia também vem desenvolvendo seu próprio sistema de posicionamento, denominado de GALILEO, retratando a importância estratégica de possuir um sistema de posicionamento.

Para eliminarem-se alguns erros de posicionamento, há o recurso da correção diferencial, feita pela utilização de um receptor fixo, num local de coordenadas conhecidas, a partir do qual se calcula o erro instantâneo na posição fornecida pelo GPS. Tal erro, após determinado, é utilizado para a correção das medidas do receptor do usuário. A correção diferencial pósprocessada é composta por uma base fixa de posição conhecida e o receptor móvel com capacidade de armazenamento de dados. Nessa base fixa, são instalados um receptor GPS e um computador para a armazenagem dos dados. Após a coleta dos dados em campo, é feito o seu processamento, cruzando-se os dados do GPS de campo com os erros determinados pela base fixa. Essa correção é valida para qualquer atividade que permita o pós-processamento, com limitações para a navegação a e aplicação de insumos em taxa variável (Molin, 2001). De acordo com Alberbo \& Thylen (1997), citado por Esquerdo (2002), essa forma de correção diferencial também pode ser obtida em tempo real, através da instalação de um rádio transmissor na base fixa e de um rádio receptor no GPS de campo.

De acordo com Mack (1997), a correção diferencial do posicionamento também se pode realizar por sinal transmitido via satélite, através do uso de estações de referência que geram um sinal transmitido por satélites geoestacionários. Há melhora significativa na qualidade do posicionamento, com acurácia de 1 metro para o posicionamento horizontal e de até 2 metros para 0 vertical. No território norte-americano, o sistema de correção WAAS ( Wide Area Augmentation System), atualmente, é controlado pelo Departamento de Aviação dos Estados Unidos (2002, http://www.faa.gov) e apresenta 
perspectivas de geração de sinal em áreas com tráfego aéreo em todo o mundo. O funcionamento do WAAS dá-se pela geração de sinal a partir de uma rede de estações de referência, sendo o sinal de correção transmitido por satélites geo-estacionários e que recebido pelo GPS, corrigindo-se o posicionamento.

Um acontecimento que melhorou a acurácia de posicionamento de receptores de GPS foi o desligamento, a partir de 1 de maio de 2000, da Disponibilidade Seletiva $(S / A)$, que é um erro proposital gerado pelo Departamento de Defesa dos Estados Unidos (OSTP, 2000).

De acordo com Balastreire \& Baio (2002), há receptores de GPS que possuem algoritmos internos para a correção de posicionamento. São programas, instalados nos receptores GPS, que minimizam o erro de posicionamento em tempo real. Ao realizarem ensaio da acurácia de posicionamento desse tipo de receptor, comparando-o a outro receptor que utiliza correção de sinal via satélite, os autores concluíram ser viável, pela qualidade, a utilização do sinal em Agricultura de Precisão.

\subsection{Altimetria em Agricultura de Precisão}

De acordo com Johnson \& Bickell (1996), as variáveis de produção podem ser agrupadas em bióticas e abióticas. Entre as variáveis abióticas, tem-se a gênese de solo, a retenção de água, a drenagem, a disponibilidade de nutrientes às plantas e outras, intimamente ligadas ao relevo, e que influenciam a produtividade das culturas. 
Verma et al. (1998) ressaltam a importância da utilização de mapas altimétricos para o manejo das áreas de Agricultura de Precisão, inclusive para obterem subsídios para a aplicação variável de agroquímicos.

Santos et al. (2001) realizaram o monitoramento de uma safra na produção de milho e encontraram baixas correlações entre a fertilidade de solo e a produtividade. Sugeriram, então, o desenvolvimento de estratégias de manejo por unidade de gerenciamento diferenciado, realizando uma análise de tendência com mais fatores que compõem a produtividade.

De acordo com Krummel \& Su (1996), há influência da altimetria do terreno na produtividade, havendo correlação com a retenção de água do solo, disponibilizando mais ou menos água para as plantas, e que afeta diretamente a produção, proporcionando assim produtividades distintas em um mesmo talhão.

Yang et al. (1998) encontraram de 13 a 35\% de respostas à variabilidade na produção de trigo devido a fatores relacionados com a altimetria. Kravchenko et al. (1999) afirmam que $20 \%$ das variáveis de produção estão correlacionadas à altimetria do terreno, como depressões, declives, bacias de retenção de água e morros. Propriedades físicas e químicas de solo, combinadas com o relevo da área, explicaram $40 \%$ da variabilidade na produção, nos estudos conduzidos pelos autores em ambientes de clima temperado, com relevo pouco acidentado.

Para recomendações de adubação, Sudduth et al. (1997) realizaram estudos visando definir a influência do solo e da altimetria do terreno sobre a disponibilização de nutrientes æ̀̀ plantas, a fim de elevar a produtividade com o uso racional de fertilizantes. Hollands (1996) encontrou correlação entre a altimetria do terreno e a disponibilidade de nitrogênio residual. Nas partes mais 
altas da lavoura, normalmente a disponibilidade é maior do que em áreas mais baixas. A detecção dessa variável de produção só foi possível a partir do uso de amostragem de solo georeferenciada e em grades da geração de mapas altimétricos com GPS. Foi detectada correlação entre os mapas de nitrogênio e os mapas altimétricos. Para adequar o número de amostras de solo, a aplicação à taxa variável de sementes, de herbicidas e de fertilizantes, o autor sugere a utilização de mapas altimétricos, de produtividade e de imagens de satélite.

Em experimentos com as culturas do trigo e canola, Pennock et al. (1999) propuseram fertilizações com nitrogênio e fósforo, de acordo com o relevo do terreno. Os autores constataram a influência do relevo na disponibilidade de nutrientes æ̀ plantas.

Kutcher et al. (1999) ressaltam a importância do levantamento altimétrico dos campos de produção. Em estudos relacionados com as culturas da canola e do trigo, constataram que a severidade de doenças relaciona-se com o relevo. Assim, propõem tratamentos com aplicações de defensivos agrícolas em doses variadas, de acordo com o relevo do terreno.

Nugteren (1999), citado por Nugteren \& Robert (2000), apresenta a correlação entre aspectos de qualidade de grãos de milho, como teor de óleo, de proteína e de amido, e o tipo de solo e suas características físicas e químicas, influenciadas pelo relevo das áreas agrícolas estudadas. Priorizar regiões no campo que possam diferenciar a produção pode vir a mudar a estratégia de manejo das áreas, uma vez que passa a existir a tendência de pagamento de prêmio para as qualidades desejadas nos grãos.

De acordo com Fridgen et al. (2000), para se obter a máxima eficiência de insumos, é necessário identificar áreas homogêneas. Para tanto, informações 
de condutividade elétrica do solo, de altimetria do terreno e do tipo de solo são de fundamental importância para o zoneamento de áreas, no sentido de definir o manejo da aplicação de insumos.

Kravchenko \& Bullock (2000) realizaram um estudo correlacionando a variabilidade da produção de milho e as características de declividade do terreno. Observaram que é possível fazer inferências quanto à distribuição da produção nas partes mais baixas e nas mais altas no terreno, bem como quanto àinfluência da altimetria do terreno nos fatores de produção de grãos.

Kravchenko et al. (2000), em uma área agrícola com monitoramento da produção, conduziram um estudo para estabelecer as correlações entre a produção de milho e de soja e a altimetria da área e os atributos de solo. As propriedades de solo explicaram $30 \%$ da variabilidade, revelando a altimetria do terreno maior influência sobre ela: as maiores produções consistentemente foram obtidas nas partes baixas do terreno. Outros fatores, como áreas com drenagem ruim e com erosão, podem explicar baixas produtividades; e fatores de solo associados com altimetria, explicaram $40 \%$ da variabilidade auferida.

Irmak et al. (2000) realizaram um estudo com o objetivo de desenvolver um procedimento eficiente para estimar as variabilidades de propriedades de solo e diagnosticar áreas onde o excesso, ou a falta de água, possam influenciar na produtividade da soja. Para tanto, realizaram levantamento do tipo de solo na área, das classes de drenagem e estudo da altimetria do terreno. Com base nesses fatores, os autores puderam compreender $90 \%$ da variabilidade da cultura da soja na área do estudo. 


\subsection{Geração de mapas altimétricos via DGPS}

Baio et al. (1998b) realizaram estudo utilizando GPS de navegação que, na ocasião, ainda estava sujeito ao erro de disponibilidade seletiva (S/A), sem correção diferencial para a obtenção de informações de altimetria. A ausência da correção não permitiu a acurácia mínima para a obtenção de coordenadas e para o levantamento de cotas.

De acordo com Molin (2000), a implementação de um sistema de Agricultura de Precisão implica um ciclo fechado de tarefas. O mapa de colheita é a informação mais completa para visualizar-se a variabilidade espacial das lavouras. Para a geração de tais mapas, o monitor de colheita das máquinas armazena, na maioria dos sistemas, arquivos textos com informações de posicionamento (latitude, longitude e altitude), fornecidas pelo receptor de DGPS, e dados da lavoura como produtividade e umidade de grãos.

Clark (1996) realizou levantamentos altimétricos em áreas agrícolas, obtendo dados através do tráfego de veículo equipado com receptor de GPS, com fase portadora L1 e com correção diferencial via rádio. Tais levantamentos garantiram um número suficiente de dados e mostram-se um método rápido e eficiente no detalhamento necessário para o manejo de áreas agrícolas. Salienta ainda o autor que o interesse agrícola sobre a altimetria ocorre para fins de manejo, não havendo a necessidade da mesma acurácia necessária para outros fins.

Clark \& Lee (1997) obtiveram mapas altimétricos de uma área de 20,2 ha, realizando o levantamento com DGPS de modo cinemático, com correção diferencial pós-processada. Utilizaram uma grade de aproximadamente 10 metros, que resultou em mapas com seis centímetros de erro para o posicionamento vertical. De acordo com Yao \& Clark (1999), é possível a 
utilização de receptor de GPS, portador das fases L1 e L2, com acurácia da ordem de 10 a 12 centímetros para levantamentos planimétricos, havendo a acurácia na mesma ordem para levantamentos altimétricos, o que é satisfatório para o uso agrícola.

Balastreire et al. (2000) realizaram avaliação de um receptor GPS para utilização agrícola, coletando dados em modo cinemático e com correção diferencial em tempo real com torre local via rádio. Obtiveram $95 \%$ dos erros entre 0,7 e 1,3 metros, para levantamentos planimétricos, e entre 0,4 a 1,4 metros, para levantamentos altimétricos.

De acordo com Yao \& Clark (1999), a acurácia na geração de mapas altimétricos em áreas planas é fundamental. Nessas áreas, erros de $10 \mathrm{~cm}$ podem comprometer a qualidade dos dados. Os autores sugerem trabalhar com acurácia de $7 \mathrm{~cm}$, considerando-se os relevos bastante planos das áreas agrícolas norte-americanas, onde trabalharam. Yao \& Clark (2000) afirmam que, para a obtenção de mapas altimétricos com maior acurácia, devem-se realizar vários levantamentos em uma mesma área, sendo o número ideal acima de cinco para a diluição do erro de posicionamento vertical.

Johansen et al. (2001) analisaram a qualidade de mapas altimétricos obtidos com um receptor GPS, com correção de sinal em tempo real. Os dados foram gerados de forma cinemática e apresentaram correlação de $82 \%$ em relação aos dados obtidos através de método convencional, com a utilização de estação total. Foram realizados seis levantamentos na mesma área, sem que melhorasse a informação na adição de dados; porém os autores consideram que os dados obtidos têm qualidade necessária para o planejamento de drenagem e para a identificação de zonas de manejo para fertilização. 
Kravchenco et al (2001) realizaram levantamentos para obter dados de altimetria e de condutividade elétrica do solo, simultaneamente, através do tráfego, em uma área, com veículo equipado com receptor de DGPS em passadas paralelas de $10 \mathrm{~m}$. Com base nessas informações, definiram classes de solo e declividade, gerando classes de drenagem em uma área de 16 ha.

Nugteren \& Robert (2001) obtiveram mapas altimétricos através da obtenção de dados de forma cinemática, pelo tráfego de um quadriciclo equipado com DGPS, em passadas paralelas de $15 \mathrm{~m}$ e velocidade de deslocamento de $5 \mathrm{~m} . \mathrm{s}^{-1}$, com oito passadas em uma mesma área. Para a reprodução do modelo de elevação do terreno, utilizaram dados que tinham como parâmetros de qualidade do sinal a diluição do posicionamento horizontal inferior a 2 e o número de satélites visados igual ou superior a 5 . Obtiveram mapa com erro de $-0,4$ a 0,4 metro, em relação ao levantamento realizado de forma convencional.

Para a reprodução de um modelo de elevação, Bucene et al. (2001) utilizaram interpolação dos dados por krigagem, obtendo correlações satisfatórias. O método de interpolação mostrou-se eficiente, resultando em um modelo de elevação do terreno através dos dados interpolados, com fidelidade a cartas planimétricas. De acordo com Vieira (2001) a interpolação por krigagem é método adequado para dados dessa natureza.

Bakhsh et al. (2000) obtiveram dados de características físicas e químicas do solo, definindo classes de solo a partir de quatro anos de cultivo em uma área agrícola com milho, bem como a reprodução do modelo numérico do terreno com a utilização de estação total. Análises geradas através de SIG e análises estatísticas levaram à conclusão de que há interação entre o tipo de solo e a altimetria, que influencia a variabilidade na produção. Sugerem a utilização de tais informações para a aplicação de insumos em doses variadas. 
Moraes et al. (2001) obtiveram um modelo de elevação de terreno a partir de dados de um receptor GPS, fase portadora L1, com correção diferencial via satélite. Para a geração do modelo, a análise espacial dos dados e a interpolação por krigagem, mostrou-se uma metodologia precisa e rápida para a obtenção de dados altimétricos a utilizar em agricultura de precisão.

Avellar et al. (2002) utilizaram sistema de informação geográfica (SIG) e aplicativos geoestatísticos na definição de subáreas para o delineamento de unidades de manejo, usando informações de produtividade de duas safras, de altimetria do terreno, com dados obtidos no monitoramento da produtividade, de fertilidade de solo e de condutividade elétrica. Com base nessas informações, encontraram quatro áreas distintas, podendo oferecer subsídios ao incremento da eficiência do manejo agrícola na área estudada.

Fraisse et al. (2001) realizaram estudo, visando a definir unidades de gerenciamento diferenciado, com base em informação de condutividade elétrica de solo e de altimetria do terreno. As combinações entre essas informações indicaram a definição de unidades de acordo com o tipo de solo. 


\section{MATERIAL E MÉTODOS}

A realização deste trabalho ocorreu em três etapas distintas. A primeira constitui-se de um ensaio preliminar para a obtenção de dados de dois receptores de GPS de mercado, a fim de avaliar a acurácia do dado de posicionamento vertical, na reprodução de dois perfis de um terreno. A segunda etapa consistiu na geração de mapas altimétricos, via DGPS, através da obtenção de dados em três simulações de colheitas de cereais e da mensuração da acurácia destes em relação ao mapa altimétrico gerado através de dados obtidos de forma convencional. Na terceira, mensurou-se a acurácia de mapas altimétricos, obtidos por dados gerados por um sistema de monitoramento de colheita, com informações de duas safras distintas e comparou-se ao mapa altimétrico gerado com dados obtidos de forma convencional.

\subsection{Avaliação da acurácia do posicionamento vertical de dois receptores de GPS}

O ensaio foi realizado no Campus Luiz de Queiroz da Universidade de São Paulo, em Piracicaba, cujas coordenadas geográficas aproximadas são: latitude 220 42' 36" S e longitude 47 $37^{\prime}$ '07' W. Foram avaliados dois perfis em superfície pavimentada que tiveram como objetivo reproduzir situações distintas que ocorrem no campo. O perfil denominado 1 , com declividade de $3,4 \%$, foi delimitado com 200 metros de comprimento e o perfil denominado 2, com declividade de 1,9\%, com 100 metros de comprimento. 
Como referência para avaliar a acurácia dos receptores de GPS, foi realizada a representação gráfica das cotas dos perfis, através de métodos topográficos. Foram previamente demarcados pontos, com a utilização de trena, realizando-se leituras e demarcando-se pontos eqüidistantes de 5 metros. Após a demarcação dos pontos, foi realizada a leitura com o auxílio de Mira Telescópica, Marca Bandeirantes ${ }^{\circledR}$ e de Nível, Marca Zeizz ${ }^{\circledR}$, modelo Ni 50, (Figura 1). A leitura foi iniciada a partir de um marco de coordenadas conhecidas, bem como altitude, próximo ao local, geo-referenciadas com GPS configurado com o Datum WGS 84.

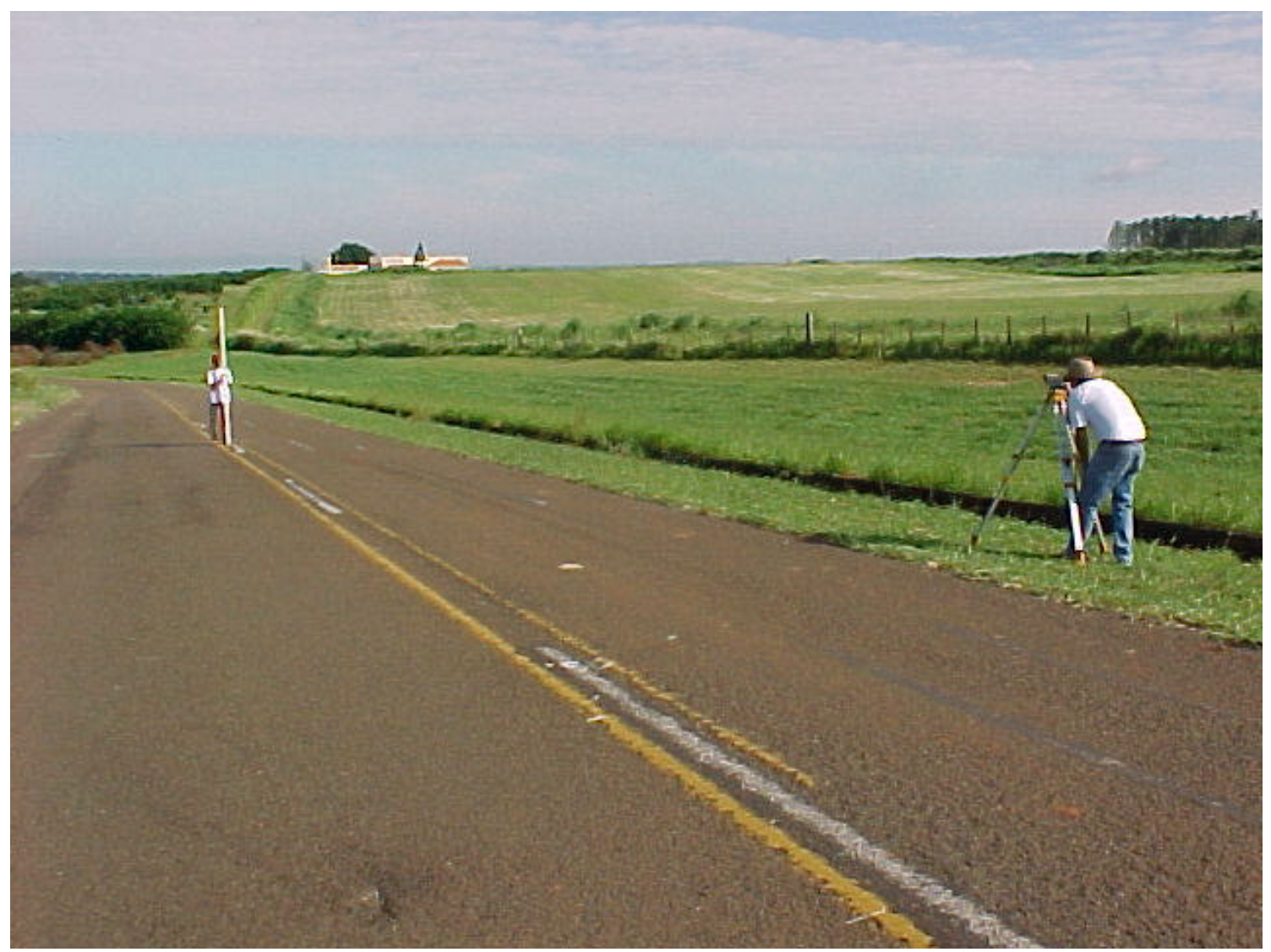

Figura 1 - Obtenção de dados para reprodução dos perfis com a utilização de mira e nível. 
Foram utilizados dois modelos de receptores de mercado (Figura 2). $\mathrm{O}$ modelo denominado 1, AG 114, Marca Trimble ${ }^{\circledR}$, de 12 canais, rastreando código $\mathrm{L} 1$, com taxa de atualização de $1 \mathrm{~Hz}$ e correção de sinal em tempo real via satélite. $O$ modelo denominado 2 , PRO XR, marca Trimble ${ }^{\circledR}$, de 12 canais, rastreando código L1, com taxa de atualização de $1 \mathrm{~Hz}$ e com correção de sinal pós-processado, ambos configurados com o Datum WGS 84.

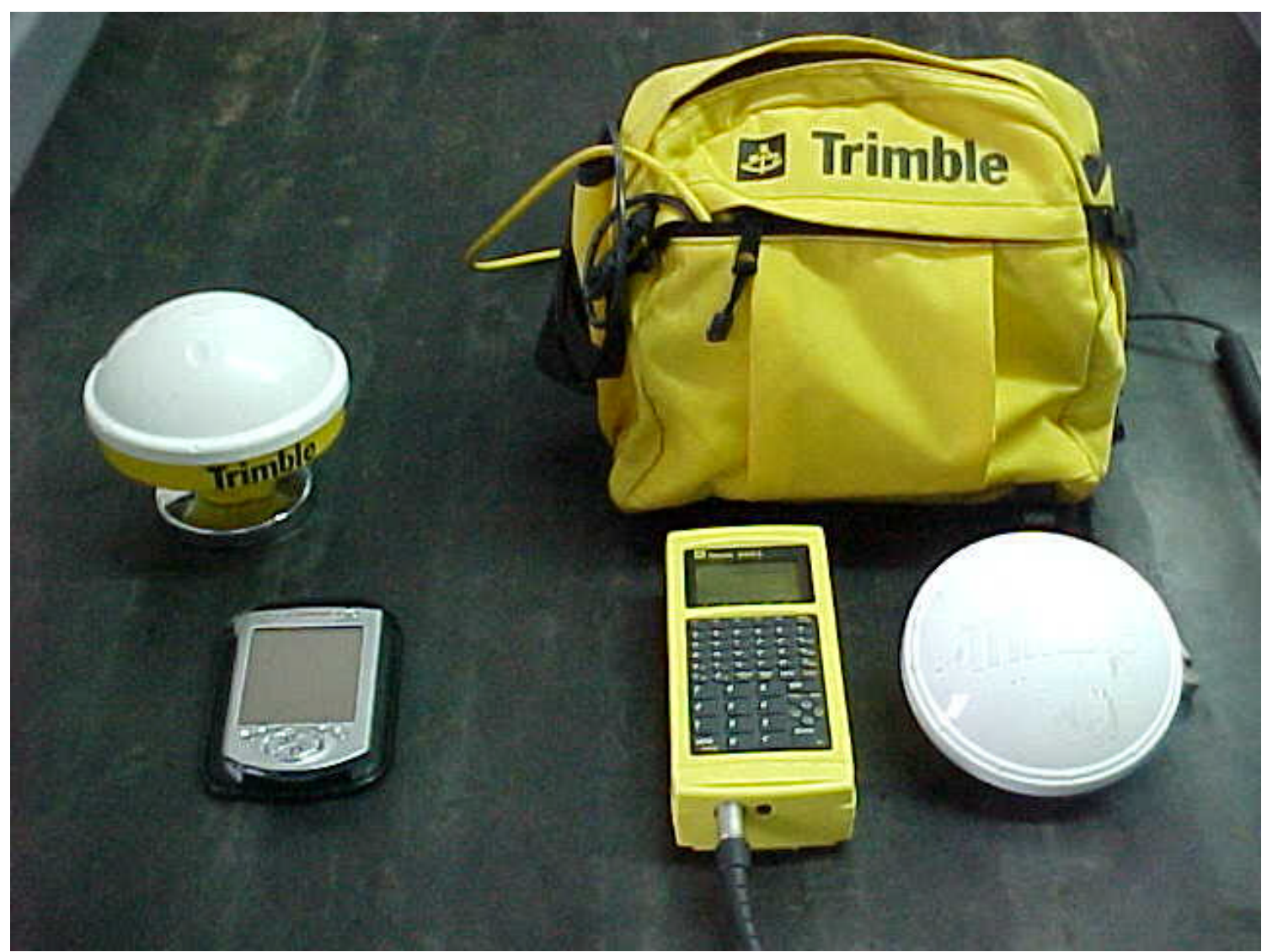

Figura 2 - Receptores de GPS utilizados para a obtenção dos dados; à esquerda receptor $\mathrm{Ag} 114$ e palm top para armazenamento dos dados; àdireita receptor PRO XR e coletor de dados TDC 1.

Os dados obtidos através do receptor de GPS 1 foram armazenados em um computador de mão, marca Compaq ${ }^{\circledR}$, modelo $\mathrm{iPAQ}$, equipado com o software Farm Site Mate (Farm Works Software ${ }^{\circledR}$ ). Os dados obtidos através do 
receptor de GPS 2 foram armazenados no coletor de dados TDC1, que acompanha o equipamento.

As obtenções de dados com receptores de GPS foram realizadas de forma cinemática, utilizando um trator agrícola Massey Ferguson® modelo MF 680. Os receptores de GPS foram instalados no trator e alimentados através de baterias de $12 \mathrm{~V}$ e as antenas foram fixadas no centro da capota (figura 3). Trafegou-se nos perfis com as velocidades de deslocamento de 1,1, 2,2 e 3,3 $\mathrm{m} \cdot \mathrm{s}^{-1}$.

A velocidade do trator foi previamente aferida em um terreno plano com tomada de tempo em uma distância de 100 metros, com três repetições. A aferição da velocidade teve como base a recomendação do fabricante na tabela de marchas e rotação. Para o deslocamento de $1,1 \mathrm{~m} \cdot \mathrm{s}^{-1}$ o trator trabalhou na terceira marcha (2B), para a velocidade de $2,2 \mathrm{~m} \cdot \mathrm{s}^{-1}$ na sétima marcha (4B) e no deslocamento a $3,3 \mathrm{~m} \cdot \mathrm{s}^{-1}$ na nona marcha (5B), todas com o motor operando a $1800 \mathrm{rpm}$. 


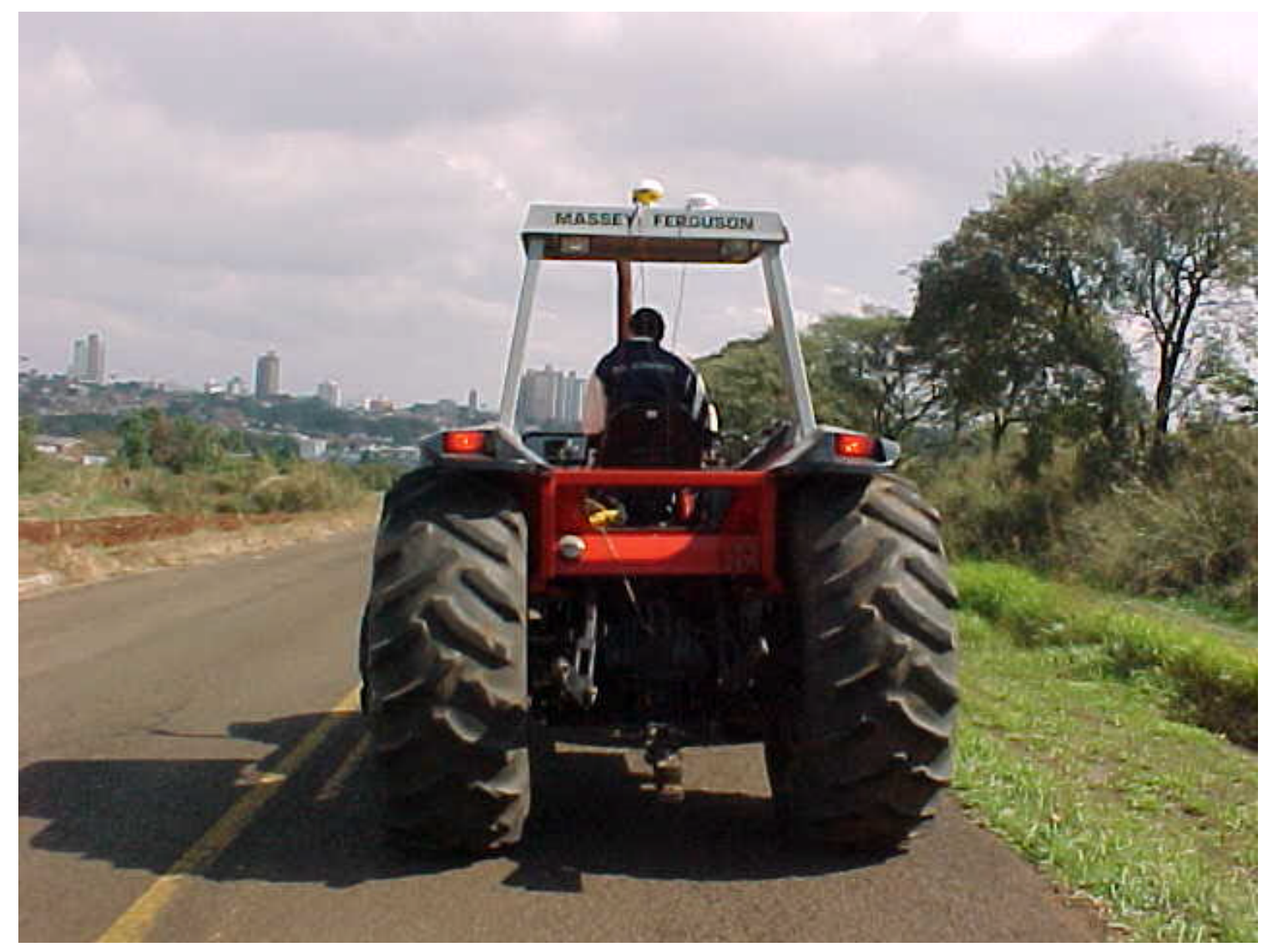

Figura 3 - Trator utilizado na obtenção dos dados e antenas dos receptores de GPS sobre a capota do trator.

Os dados obtidos através do receptor de GPS 1 foram transformados por meio de planilha eletrônica em coordenadas UTM (Universal Transversa de Mercator), a fim de proceder-se àreprodução do perfil com a locação das cotas.

Após a conversão dos dados, fez-se a comparação entre as cotas obtidas pelo sistema tradicional e as obtidas pelos receptores de GPS: igualaram-se as latitudes $\mathrm{e}$ as longitudes conseguidas pelos dois métodos, obtendo-se as diferenças de cotas de mesma localização, o que possibilitou gerar a informação do erro vertical fornecido pelo receptor de GPS para cada ponto. Após esse processo obteve-se a dispersão dos erros e a freqüência dos erros encontrados para cada ponto. 
Para os dados obtidos através do receptor de GPS 2, os dados armazenados no receptor TDC1 foram exportados a um computador no software Pathfinder (Trimble $\left.{ }^{\circledR}\right)$. Procedeu-se então, a correção do posicionamento dos arquivos, através de informações geradas pela antena base instalada no CIAGRI/USP, Campus "Luiz de Queiroz", com as seguintes

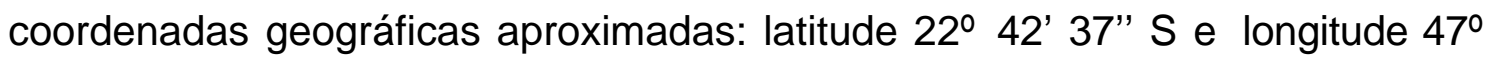
38' 06" W. Na seqüência, os dados receberam o mesmo tratamento aplicado aos obtidos através do receptor de GPS 1.

\subsection{Obtenção de mapas altimétricos via DGPS em simulações de colheitas de cereais}

$\mathrm{Na}$ segunda etapa do trabalho, foram gerados três conjuntos de dados, simulando operações de colheita de cereais. As simulações foram realizadas em dois dias, com o intuito de reunir informações que não seria possível de se obter em época de colheitas, devido ao espaço de tempo para a realização deste trabalho. Os dados de altimetria foram obtidos em uma área agrícola de 6,9 hectares, cultivada com grãos em sistema de plantio direto e localizada no Campus da USP, em Pirassununga, no Estado de São Paulo, cujas coordenadas geográficas aproximadas são: latitude 21 $57^{\prime} 36^{\prime \prime}$ S e longitude 47 46' 53" W. Nessa área, realizou-se levantamento altimétrico de forma convencional, obtendo-se de dados por estação total, Marca Pentax®, Modelo R $115 \mathrm{~N}$, precisão angular de 5", precisão para distância $1 \mathrm{~mm}$ e gerando a informação de longitude, latitude e altitude para vários pontos. As leituras das cotas foram realizadas a partir de um ponto conhecido geo-referenciado com GPS configurado com o Datum WGS 84. 
Após a coleta dos dados, foi realizada a reprodução gráfica da elevação do terreno, com a espacialização dos dados no software SSTollsBox (SST Develpoment Group $\left.{ }^{\circledR}\right)$. Essa informação foi a base para compararem-se os dados obtidos com receptor de GPS e aqueles de forma convencional. Os dados de GPS foram gerados utilizando-se o receptor AG 114, marca Trimble ${ }^{\circledR}$, configurado com o Datum WGS 84 com correção de sinal via satélite em tempo real, gerada pela empresa Racal ${ }^{\circledR}$.

Para a obtenção dos dados, foi utilizado um trator agrícola Massey Ferguson $\AA$, modelo MF 265, previamente aferido em terreno plano, para trabalhar na velocidade de deslocamento de $1,6 \mathrm{~m} \cdot \mathrm{s}^{-1}$. A decisão de trabalharse nessa velocidade e a utilização de correção de posicionamento em tempo real foi tomada visando simular condições encontradas na colheita de cereais.

O receptor de GPS foi instalado no trator e alimentado por bateria de 12 V. Os dados foram armazenados em um computador de mão, marca Compaq ${ }^{\circledR}$, modelo iPAQ, equipado com software de navegação Farm Site Mate (Farm Works Software $\left.{ }^{\circledR}\right)$. A antena do receptor de GPS foi fixada no centro do protetor solar do trator. Para o balizamento do percurso do trator na área, foi acoplado ao seu engate de três pontos um sulcador com duas hastes, espaçadas quatro metros entre si.

No dia 03 de agosto de 2001, obtiveram-se dois conjuntos de dados na área, simulando duas operações de colheita. Realizou-se um terceiro levantamento da mesma área no dia 04 de agosto de 2001, gerando-se a terceira simulação da área.

Os dados gerados em campo, após o procedimento de conversão de arquivo texto para arquivo de planilha eletrônica, receberam tratamento para a 
eliminação dos registros com valores nulos de altimétria. Para a eliminação desses dados, foi utilizado o recurso de classificação por ordem crescente.

Na seqüência, procedeu-se à análise estatística descritiva e analise geoestatísca dos dados, obtendo-se os semivariogramas e os parâmetros para a interpolação por krigagem. Para a confecção dos semivariogramas utilizou-se o programa GS +(Gamma Desingn Software $\left.{ }^{\circledR}\right)$.

Após a editoração dos arquivos, os dados foram importados para o SIG dedicado à Agricultura de Precisão SStollBox (SST Developement Group ${ }^{\circledR}$ ), onde foram geradas as superfícies por interpolação para a reprodução gráfica da área.

Para a reprodução do modelo de elevação do terreno, foram adotados dois critérios distintos. Gerou-se o modelo de elevação do terreno com a interpolação dos dados pelo método de krigagem e a representação gráfica com células de 5,10 e $20 \mathrm{~m}$, tanto para os dados obtidos pelo método convencional quanto para os dados das simulações da operação de colheita de cereais e para a junção dos dados das mesmas. Os valores da cota de cada célula, para os modelos de elevação obtidos pelo método convencional, foram comparados com os valores da cota de cada célula dos modelos de elevação obtidos com dados de receptor de GPS. Esse critério foi denominado comparação por células.

O segundo critério constituiu-se na comparação das cotas do modelo de elevação, obtido com os dados do método convencional, com as cotas representadas pela média de dados provenientes do receptor de GPS, em raios de busca de 4, 8, e $12 \mathrm{~m}$ em torno das cotas obtidas pelo método convencional. Esse critério foi denominado comparação por raio de busca. 
Realizou-se, ainda, a junção da primeira e da segunda simulação de coleta de dados, da primeira com a terceira e da segunda com a terceira simulação, bem como das três simulações, visando considerar o acúmulo de dados de altimetria de diferentes colheitas.

\subsection{Mapas altimétricos obtidos com monitor de produtividade}

A área agrícola estudada vêm sendo monitorada desde 1998 em projeto de pesquisa conduzido pelo Departamento de Engenharia Rural da ESALQ/USP. Em julho de 2001, realizou-se a colheita de soja utilizando uma colhedora John Deere $\AA$, Modelo 9750 STS, equipada com o sistema de monitoramento da produção de grãos GreenStar ${ }^{\circ}$, com o receptor de GPS de 12 canais, configurado com o Datum WGS 84, com correção diferencial via satélite, em tempo real, com sinal gerado pela empresa Oministar ${ }^{\circledR}$. Foram coletados dados com a freqüência de um dado por segundo, obtendo as informações de longitude, de latitude e de altitude e os demais dados pertinentes àcolheita da soja. Na mesma área, em abril de 2002, foi realizada a colheita de milho da safra 2001/2002, com a mesma colhedora e o mesmo sistema de obtenção de dados.

Os dados de longitude, de latitude e de altitude foram tratados da mesma forma descrita para os dados do item 3.2, obtendo-se a reprodução gráfica do modelo de elevação do terreno. A junção dos dados da colheita das safras de soja e milho, aqui denominadas de colheitas 1 e 2 , respectivamente, foi analisadas com os mesmos parâmetros que os utilizados anteriormente. 


\section{RESULTADOS E DISCUSSÃO}

Os resultados deste trabalho estão divididos em três etapas. A primeira, com resultados pertinentes à acurácia do posicionamento vertical de dois receptores de GPS. A segunda etapa, com resultados referentes à acurácia de mapas altimétricos obtidos com receptor de GPS, com correção de sinal em tempo real, via satélite simulando a operação de colheita de cereais. Na terceira etapa, foi analisada a acurácia de mapas altimétricos, obtidos a partir de dados coletados em monitoramento de produtividade da colheita de grãos num sistema comercial.

\subsection{Acurácia do posicionamento vertical de dois receptores de GPS}

$\mathrm{Na}$ Tabela 1, são apresentados os erros de altitude obtidos com os receptores de GPS e avaliados em relação aos dados obtidos pelo método topográfico. 
Tabela 1. Resultados da análise estatística descritiva dos erros de altitude dos dados obtidos com os receptores de GPS, avaliados em dois perfis, em relação aos dados do levantamento realizado pelo método topográfico.

\begin{tabular}{|c|c|c|c|c|c|c|c|}
\hline \multirow[b]{2}{*}{ Perfil } & \multirow[b]{2}{*}{$\begin{array}{c}\text { Velocidades } \\
\text { de } \\
\text { deslocamento } \\
\left(\mathrm{m}^{-1} \mathrm{~s}^{-1}\right)\end{array}$} & \multirow[b]{2}{*}{ GPS } & \multicolumn{5}{|c|}{ Erro de altitude } \\
\hline & & & $\begin{array}{c}\text { Média } \\
(\mathrm{m}) \\
\end{array}$ & (m) & Amplitude & $\begin{array}{c}\text { Valores } \\
\text { Negativos } \\
(\%) \\
\end{array}$ & $\begin{array}{c}\text { Valores } \\
\text { Positivos } \\
(\%) \\
\end{array}$ \\
\hline 1 & 1,1 & 1 & $-0,5$ & $-0,4$ & 3,8 & 54,3 & 45,7 \\
\hline 1 & 2,2 & 1 & $-0,6$ & $-0,5$ & 3,2 & 57,3 & 42,7 \\
\hline 1 & 3,3 & 1 & $-0,4$ & $-0,3$ & 4,4 & 55,6 & 44,4 \\
\hline 1 & 1,1 & 2 & $-1,5$ & $-1,1$ & 5,2 & 78,2 & 21,8 \\
\hline 1 & 2,2 & 2 & $-0,3$ & $-0,4$ & 3,9 & 63,6 & 36,4 \\
\hline 1 & 3,3 & 2 & $-0,8$ & $-0,5$ & 5,1 & 67,9 & 32,1 \\
\hline 2 & 1,1 & 1 & 0,2 & 0,2 & 3,0 & 46,5 & 53,5 \\
\hline 2 & 2,2 & 1 & 0,4 & 0,5 & 2,7 & 23,2 & 76,8 \\
\hline 2 & 3,3 & 1 & 0,9 & 1,0 & 2,4 & 0 & 100 \\
\hline 2 & 1,1 & 2 & 0,2 & 0,2 & 2,8 & 45,0 & 55 \\
\hline 2 & 2,2 & 2 & 0,8 & 0,8 & 4,8 & 21,2 & 78,8 \\
\hline 2 & 3,3 & 2 & 1,1 & 1,2 & 2,7 & 0 & 100 \\
\hline
\end{tabular}

Na Figura 4, é apresentada a freqüência acumulada do erro em módulo, dos dados obtidos com o receptor GPS 1, nos dois perfis, para as três velocidades de deslocamento.
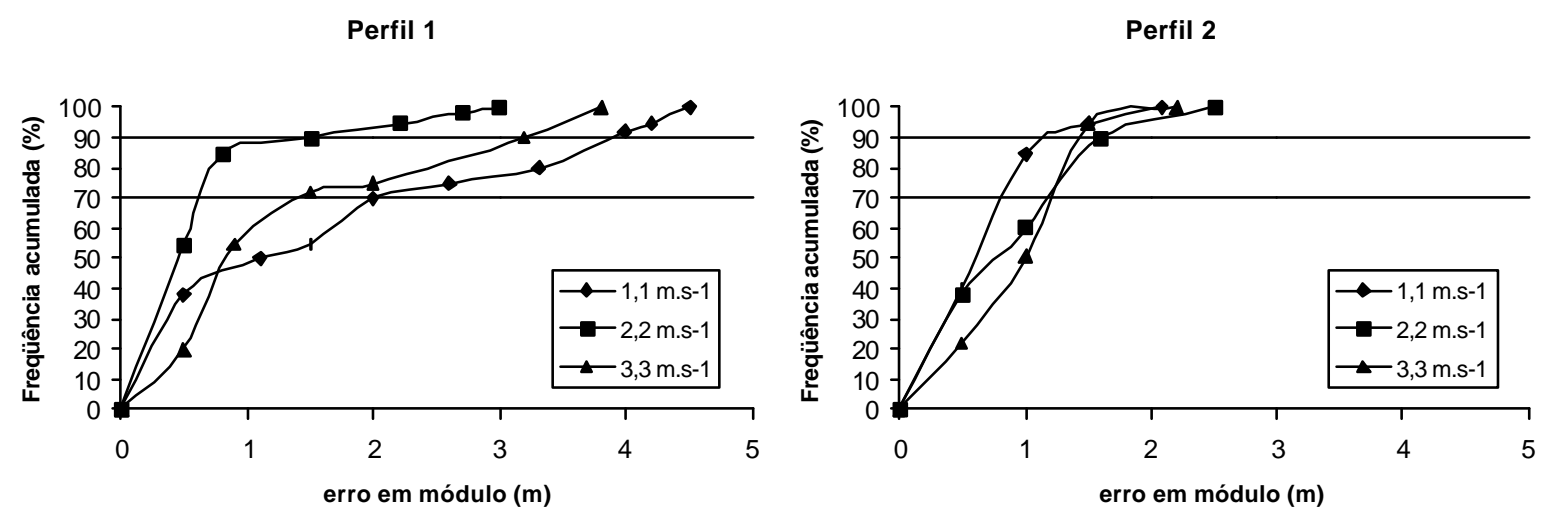

Figura 4 - Representação gráfica da freqüência acumulada do erro em módulo, para o receptor de GPS 1, nas três velocidades de deslocamento. 
Para o perfil com declividade de $3,4 \%$ (perfil 1 ), os dados que tiveram freqüência mais baixa de erros em módulo foram os obtidos àvelocidade de 2,2 $\mathrm{m} \cdot \mathrm{s}^{-1}$. Entre eles, $70 \%$, encontram-se abaixo de $1,0 \mathrm{~m}$, qualidade que não foi encontrada nos dados com as velocidades de deslocamento de 3,3 e 1,1 m.s ${ }^{-1}$, com erros máximos de 5,0 m para o posicionamento vertical. Para os dados obtidos no perfil de 1,9\% de declividade (perfil 2), $70 \%$ dos erros estão em torno de $1,0 \mathrm{~m}$ e, para $90 \%$, os erros estão até $1,5 \mathrm{~m}$, com um erro máximo de $2,8 \mathrm{~m}$.

Na Figura 5, é apresentada a freqüência acumulada do erro em módulo, dos dados obtidos com o receptor de GPS 2, nos dois perfis.

Perfil 1

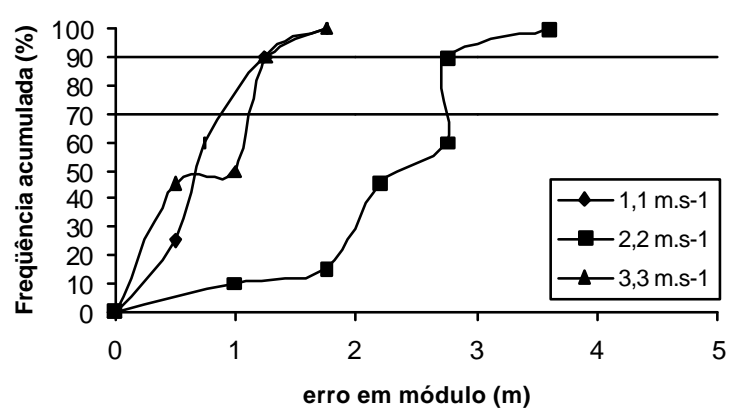

Perfil 2

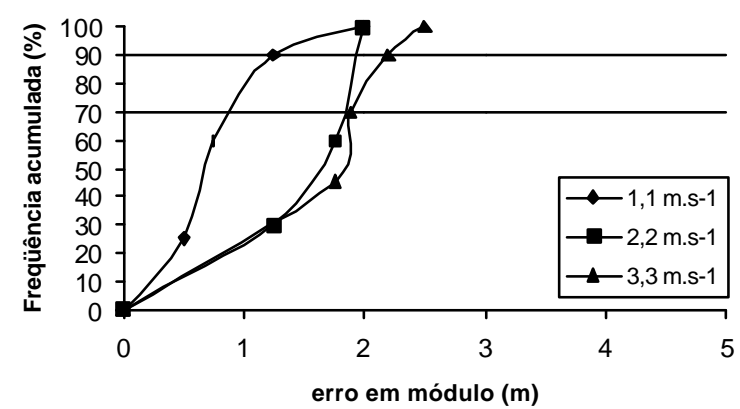

Figura 5 - Representação gráfica da freqüência acumulada do erro em módulo, para o receptor de GPS 2, nas três velocidades de deslocamento.

Os dados obtidos no perfil com declividade de 3,4\% (perfil 1) apresentam boa qualidade para os levantamentos realizados a 1,1 e a $3,3 \mathrm{~m} \cdot \mathrm{s}^{-1}$, com $70 \%$ dos dados apresentando erro em módulo próximo a 1,0 metro. Porém o levantamento realizado a 2,2 $\mathrm{m} \cdot \mathrm{s}^{-1}$ apresenta qualidade inferior, com erros ao redor de 2,5 m. Para o perfil 2, apenas os valores obtidos com velocidade de deslocamento de 1,1 m.s ${ }^{-1}$ apresentam o mesmo padrão em relação ao perfil 1 . Para os demais levantamentos, $70 \%$ dos valores estão próximos a 2,0 m. 
Os dados obtidos no perfil 1 apresentam o mesmo comportamento para os dois receptores de GPS, com valores negativos prevalecendo sobre os positivos, gerando erros médios negativos e subestimando a altitude do perfil avaliado. Já para os erros mensurados no perfil 2, ocorreu a inversão da tendência encontrada no perfil 1, com o predomínio de valores e erros médios positivos.

Os levantamentos dos perfis foram realizados com pequenos intervalos de tempo entre si e no mesmo dia. A forma de correção diferencial não influenciou no comportamento dos dados, tendo o mesmo padrão para as duas formas de correção avaliadas.

Como não houve influência da forma de correção, a variação dos comportamentos dos erros pode ser explicada pela declividade dos perfis. No perfil 1, mais declivoso, foram subestimados os valores de altitude e no perfil 2, menos declivoso, foram superestimadas as cotas do terreno. Esse foi o padrão encontrado nos perfis avaliados, não sendo possível uma conclusão.

Na Figura 6, é apresentada a freqüência acumulada do erro em módulo dos dados obtidos com os dois receptores de GPS, nos dois perfis, como média das três velocidades de deslocamento. 
Perfil 1

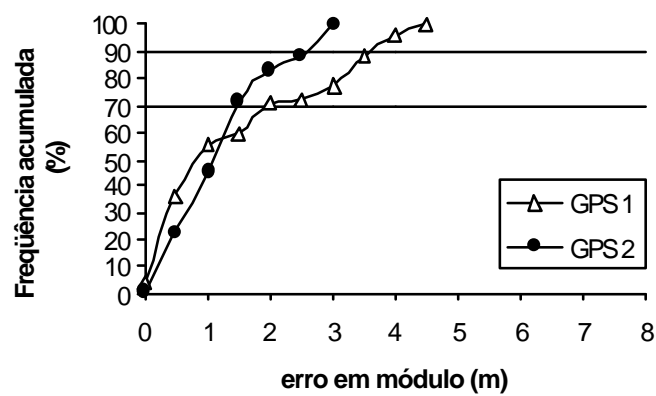

Perfil 2

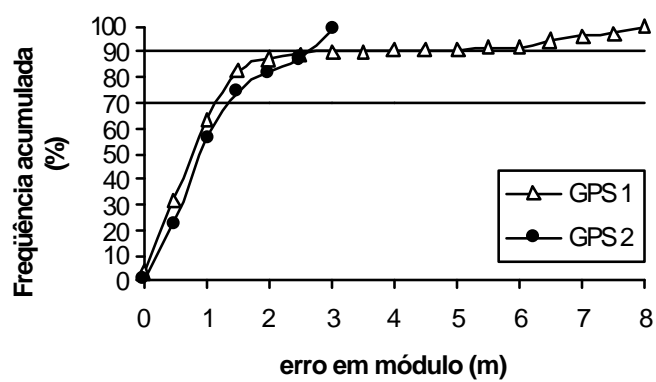

Figura 6 - Freqüência acumulada do erro em módulo para os dois perfis como média das três velocidades de deslocamento para cada receptor de GPS.

Nos dois perfis avaliados, o receptor de GPS 2, com correção de sinal pósprocessada, apresentou melhor acurácia do que o receptor de GPS 1, com correção de sinal via satélite. O padrão de erro foi semelhante nos dois perfis avaliados, com $70 \%$ dos valores abaixo de 2,0 metros e com valores máximos em torno de 3 metros. O receptor de GPS 1 apresentou melhores resultados no perfil 2, que é mais plano do que o perfil 1 , com $70 \%$ dos dados abaixo de 2,0 metros, porém com erros de até 8 metros. Para o perfil 2, observa-se que $70 \%$ dos dados estão ao redor de 2,5 metros e os erros máximos em torno de 5,0 metros. Neste ensaio, a correção de sinal por pós-processamento apresentou melhor acurácia do que a correção de sinal em tempo real via satélite.

\subsection{Acurácia de mapas altimétricos, via DGPS, obtidos através de simulação de colheita de cereais}

A segunda etapa deste trabalho constitui em obter mapas altimétricos de forma convencional, com estação total, em comparar esse levantamento com os dados obtidos por receptor de DGPS, em simulações de colheita de cereais. $\mathrm{Na}$ Figura 7, é apresentada a distribuição dos pontos amostrais do método convencional de levantamento altimétrico. 


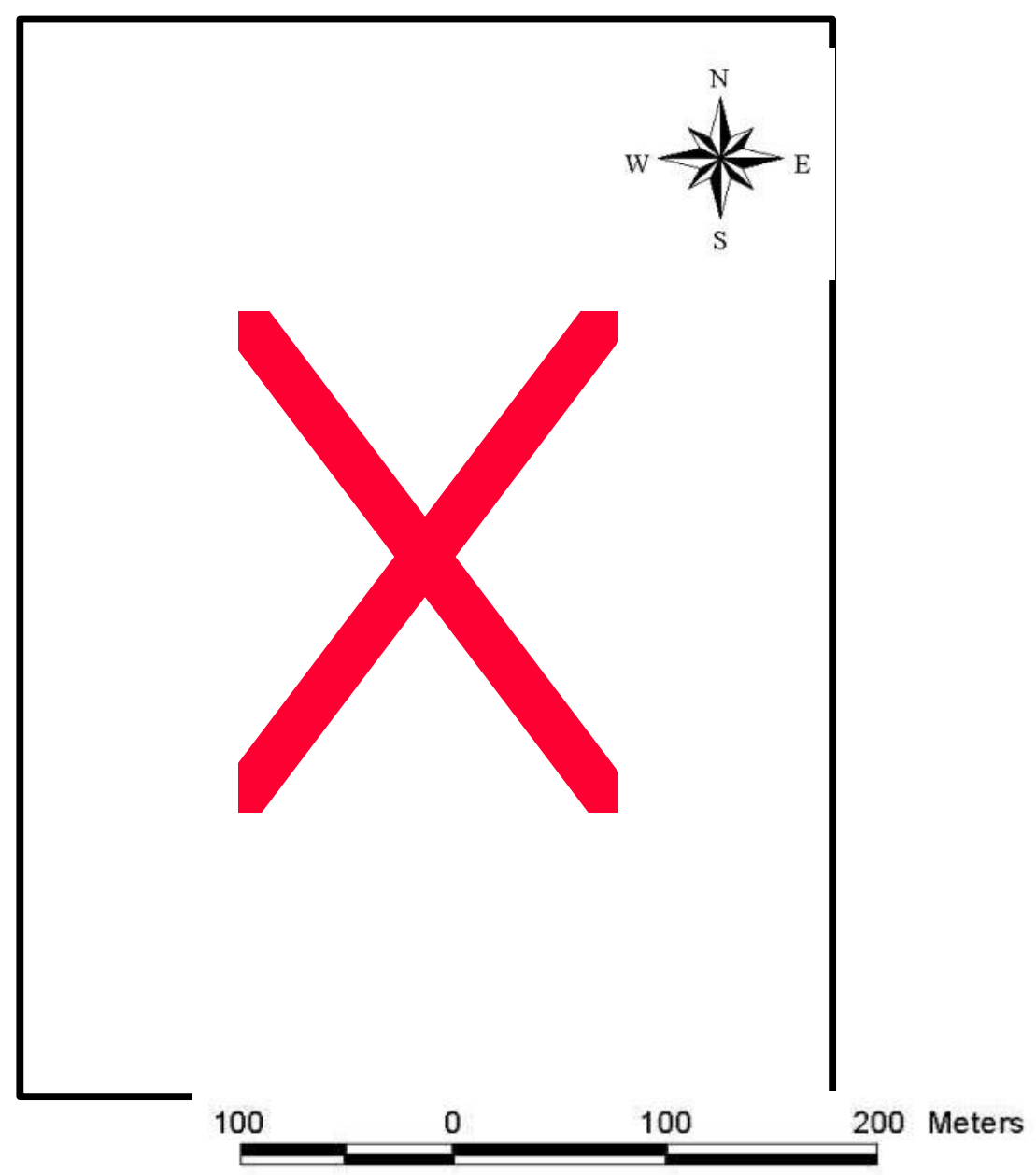

Figura 7 - Área agrícola de 6,9 ha, mostrando os pontos onde foram coletados os dados para o levantamento topográfico convencional com o uso de uma estação total.

Na Figura 8, é apresentado o modelo de elevação do terreno obtido pelo levantamento convencional e a interpolação por krigagem. 


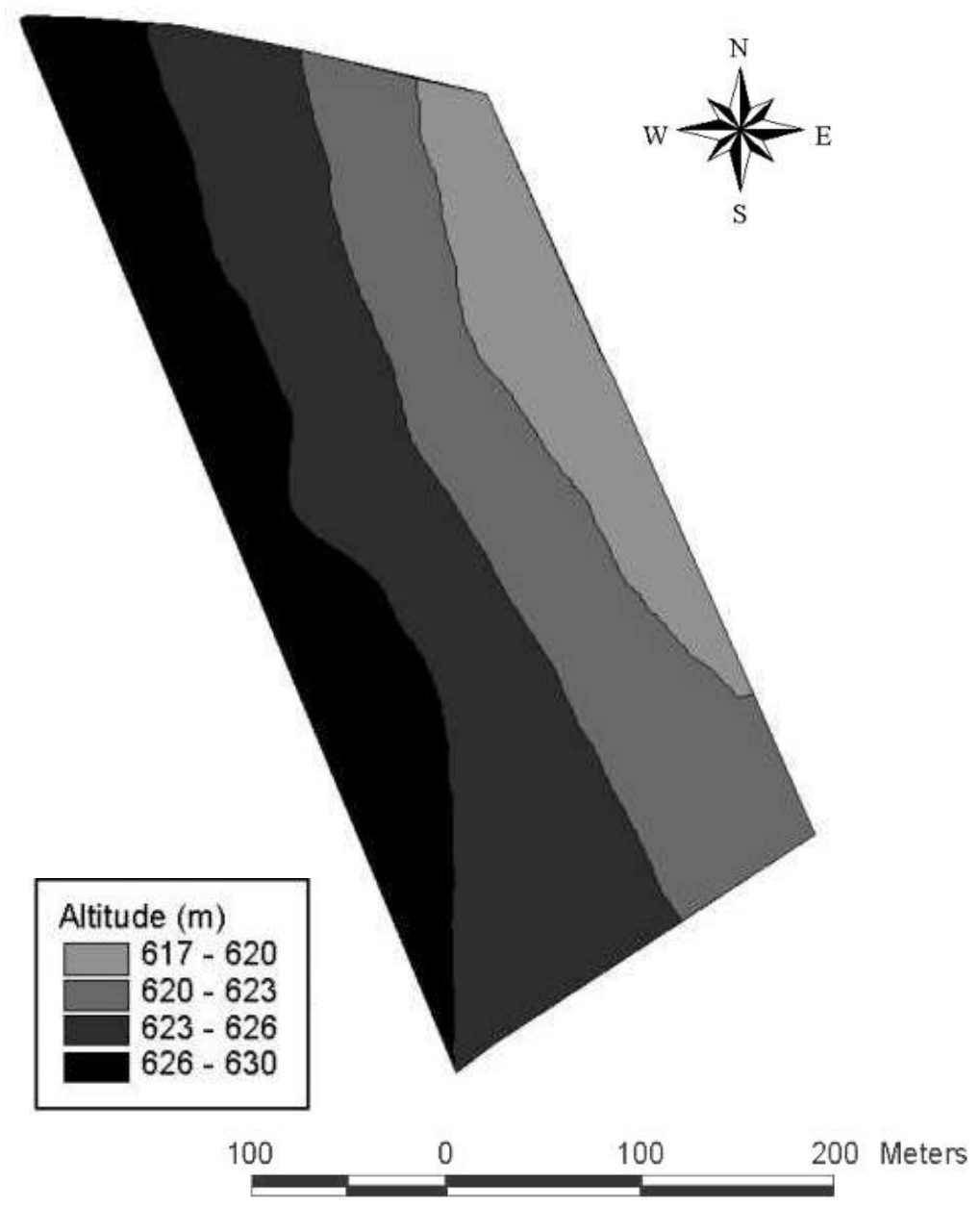

Figura 8 - Modelo de elevação do terreno obtido pelo método convencional e interpolação dos dados por krigagem.

A área em estudo apresenta desnível predominante de noroeste a sudeste, em torno de 6,8\%, com suaves ondulações na longitudinal.

$\mathrm{Na}$ tabela 2, são apresentados os erros de altitude obtidos com o receptor de GPS, em relação aos dados obtidos pelo método convencional. 
Tabela 2. Resultados da análise estatística descritiva dos erros de altitude, obtidos pelo receptor de GPS em simulações de colheitas de cereais, em relação aos dados do levantamento realizado pelo método convencional.

\begin{tabular}{cccccccc}
\hline \multirow{2}{*}{$\begin{array}{c}\text { Simulação } \\
\text { de colheita }\end{array}$} & Critério & \multicolumn{7}{c}{ Erro de Altitude } \\
\cline { 3 - 7 } & & Média & Mediana & Amplitude & $\begin{array}{c}\text { Valores } \\
\text { Negativos }\end{array}$ & $\begin{array}{c}\text { Valores } \\
\text { Positivos } \\
(\%)\end{array}$ & $\begin{array}{c}\text { Valores } \\
\text { Nulos } \\
(\%)\end{array}$ \\
\hline 1 & Células de $5 \mathrm{~m}$ & $-0,2$ & $-0,3$ & 8,2 & 56,2 & 41,2 & 2,6 \\
1 & Células de 10m & $-0,2$ & $-0,3$ & 7,9 & 54,9 & 42,8 & 2,3 \\
1 & Células de 20m & $-0,1$ & 0,3 & 8,1 & 56,4 & 40,8 & 2,8 \\
1 & Raio de 4m & $-0,7$ & $-0,8$ & 7,4 & 73,5 & 26,5 & 0,0 \\
1 & Raio de 8m & $-0,6$ & 0,2 & 6,3 & 64,9 & 35,1 & 0,0 \\
1 & Raio de 12m & $-0,5$ & $-0,9$ & 5,8 & 60,3 & 39,7 & 0,0 \\
2 & Células de 5m & $-0,4$ & $-0,4$ & 10,8 & 54,5 & 42,8 & 2,7 \\
2 & Células de 10m & 1,8 & 1,8 & 10,4 & 20,6 & 78,1 & 1,3 \\
2 & Células de 20 m & $-0,1$ & 0,1 & 8,1 & 50,2 & 48,0 & 1,8 \\
2 & Raio de 4m & 1,5 & 1,5 & 8,6 & 27,3 & 72,7 & 0,0 \\
2 & Raio de 8m & 1,4 & 1,3 & 5,0 & 21,1 & 78,9 & 0,0 \\
2 & Raio de 12m & 1,4 & 1,3 & 5,0 & 23,8 & 76,8 & 0,0 \\
3 & Células de 5m & 1,2 & 1,4 & 11,3 & 22,8 & 75,2 & 2,0 \\
3 & Células de 10m & 1,2 & 1,4 & 9,4 & 23,1 & 75,5 & 1,4 \\
3 & Células de 20m & 1,2 & 1,6 & 9,1 & 22,3 & 76,3 & 1,4 \\
3 & Raio de 4m & 0,8 & 0,6 & 8,1 & 37,8 & 62,2 & 0,0 \\
3 & Raio de 8m & 0,8 & 0,5 & 8,4 & 35,2 & 64,8 & 0,0 \\
3 & Raio de 12m & 0,8 & 0,6 & 7,0 & 33,9 & 66,1 & 0,0 \\
\hline
\end{tabular}

Na Figura 9, é apresentada a reprodução gráfica dos módulos dos erros de altitude dos mapas altimétricos obtidos com DGPS, em passadas paralelas do trator simulando colheitas de cereais, em relação ao levantamento realizado de forma convencional, utilizando-se o critério de comparação por células. 
Simulação 1

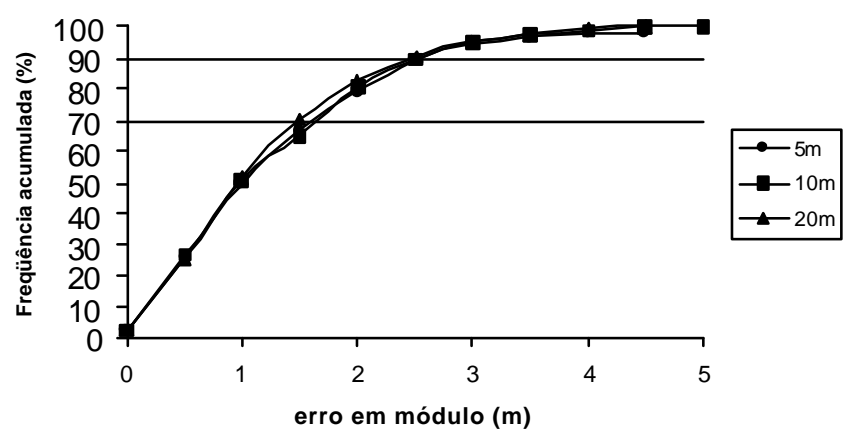

Simulação 2

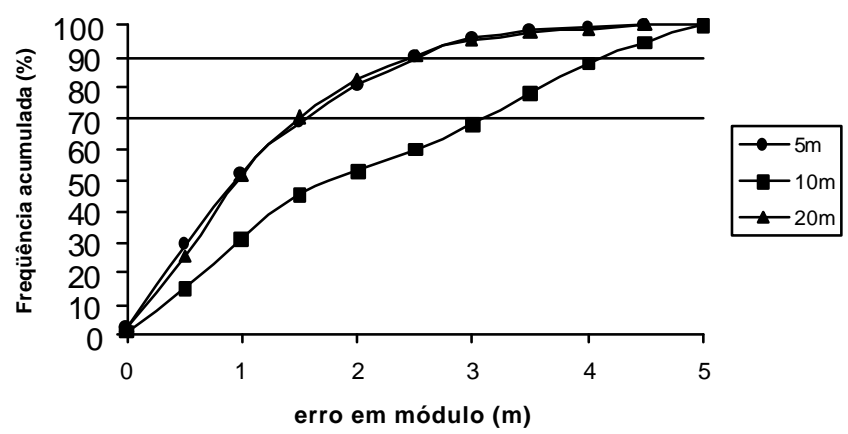

Simulação 3

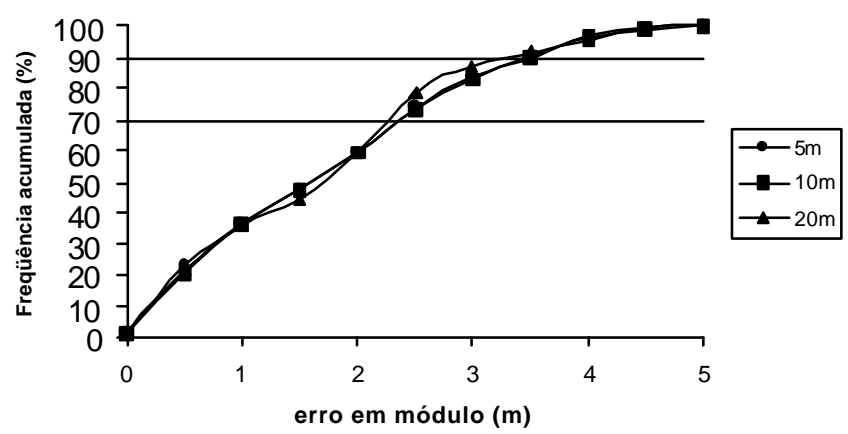

Figura 9 - Freqüência acumulada do módulo do erro para as três simulações de operação de colheita, obtidas pelo critério de comparação por células. 
O conjunto de dados obtido na simulação 1 apresenta maior percentual de erros negativos, com valores em módulo maiores que os valores positivos, gerando erro médio negativo e com tendência de subestimar as cotas da área estudada. Para a simulação 2 , houve a inversão da tendência com a superestimação das cotas, o mesmo ocorrendo com o conjunto de dados obtidos na terceira simulação.

As diferenças encontradas entre as simulações podem ter sido ocasionadas pelo arranjamento dos satélites visados. A simulação 1 foi realizada no dia 03 de agosto de 2001, no período da manhã; a segunda simulação, no mesmo dia, no período da tarde e a terceira simulação, no dia seguinte, no período da manhã. Realizou-se a junção de dados para avaliar se haveria melhora da qualidade da informação, em relação aos conjuntos de dados originais, em função da maior quantidade de dados para representar uma mesma área.

Na simulação $170 \%$ dos dados de módulo de erro ficaram ao redor de 1,8 m, correspondente ao desvio-padrão. Para $90 \%$ dos dados, o módulo do erro está ao redor de 2,5 m.. Para a simulação 2, os mesmos níveis de acurácia são encontrados, exceto para a representação gráfica obtida com a célula de $10 \mathrm{~m}$. $\mathrm{Na}$ simulação 3, os dados apresentam a pior qualidade em relação à duas primeiras, com $70 \%$ dos dados ao redor de $2,5 \mathrm{~m}$ e $90 \%$ dos dados em torno de 3,8 m. Para as três simulações, o erro em módulo máximo está em torno de $5,0 \mathrm{~m}$.

$\mathrm{Na}$ tabela 2 observa-se que as simulações 1 e 2 apresentam padrão semelhante em relação ao erro, com valores negativos em torno de $55 \%$. A amplitude média é de 8,0 $\mathrm{m}$ para a simulação 1 e de $9,8 \mathrm{~m}$ para a simulação 2 , enquanto que para a terceira simulação os erros negativos correspondem a $75 \%$ das observações com amplitude média de 9,9 m. 
Quanto ao tamanho da célula para comparação, apenas na segunda simulação as células de $10 \mathrm{~m}$ tiveram menor acurácia em relação às demais.

A Figura 10, apresenta a freqüência acumulada do erro em módulo para as simulações, com resultados obtidos pelo critério de comparação pelo raio de busca. 
Simulação 1

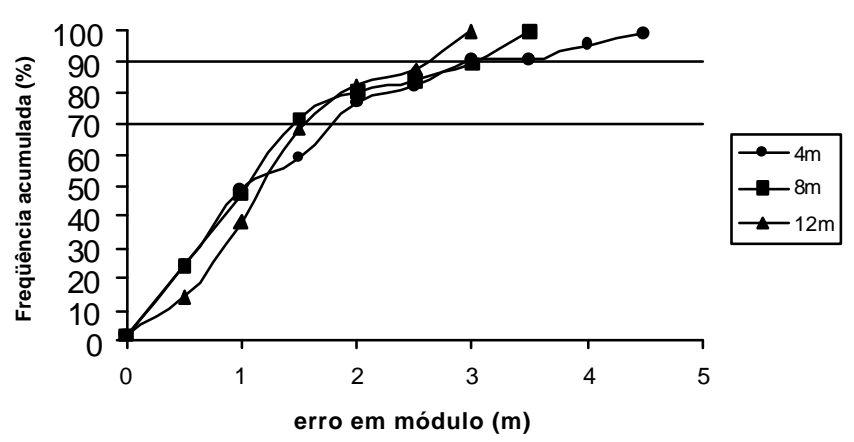

Simulação 2

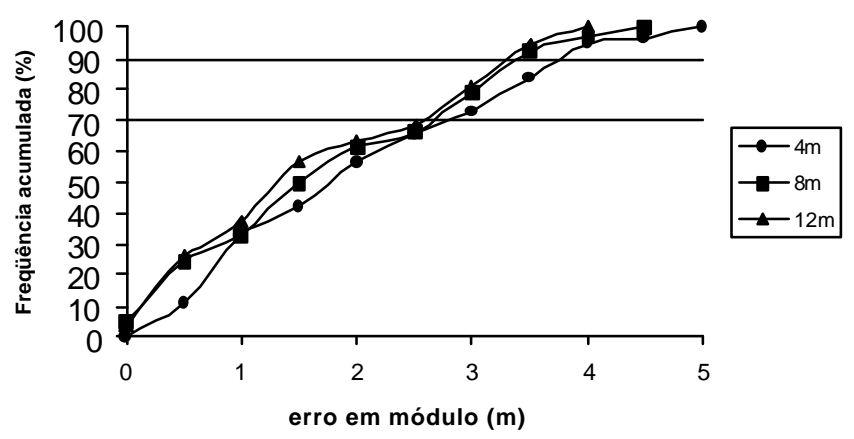

Simulação 3

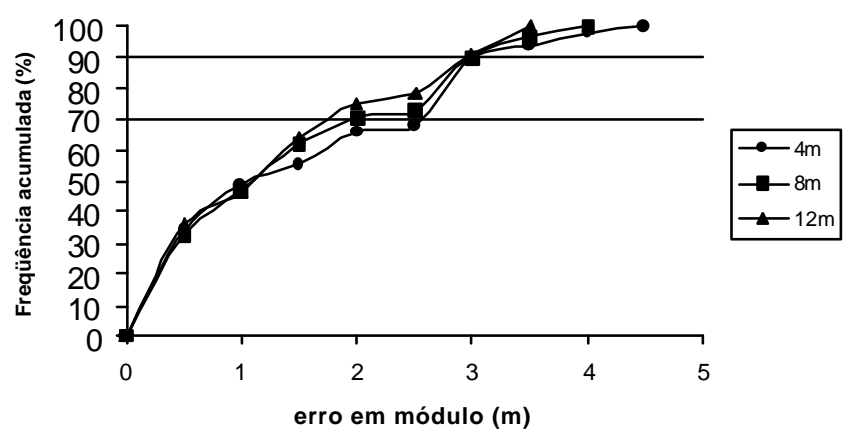

Figura 10 - Freqüência acumulada do módulo do erro, para as três simulações de operação de colheita, pelo critério de comparação pelo raio de busca. 
As freqüências acumuladas não apresentam o mesmo comportamento em relação æ̀ encontradas nas interpolações por células, com níveis de acurácia distintos entre as três simulações.

Para a simulação 1, 70\% dos dados apresentam erro em módulo ao redor de 1,5 m, e para $90 \%$ dos dados, em torno de 2,8 m. Na simulação 2, os erros resultam ao redor de 2,5 m para $70 \%$ dos dados e valores de erros em torno de $3,5 \mathrm{~m}$ para $90 \%$ dos dados. Para a terceira simulação, $70 \%$ dos dados resultaram em erros próximos a 2,0 m e 90\% dos erros, em torno de 3,0 m.

As freqüências acumuladas obtidas com $12 \mathrm{~m}$ de raio de busca apresentam erro em módulo máximo menor que os erros máximos em módulo das freqüências obtidas com $8 \mathrm{~m}$ e $4 \mathrm{~m}$ de raio de busca. Nas três simulações de operação de colheita de cereais, o erro máximo não ultrapassou 5 metros. Como apresentado na tabela 2, observa-se que para a simulação 1 cerca de $65 \%$ dos dados são de valores negativos e, nas simulações 2 e 3 a maior parte dos valores são positivos com $75 \%$ e $65 \%$ respectivamente. As amplitudes médias de 6,5 m para a simulação 1, de 6,2 $\mathrm{m}$ para a simulação 2 e de 7,8 $\mathrm{m}$ para a simulação 3 .

Na Figura 11, são apresentadas as freqüências acumuladas da junção de dados das diferentes simulações de operação de colheita de cereais, com dados obtidos pelo critério de comparação por células. 
Junção da simulação 1 com a simulação 2

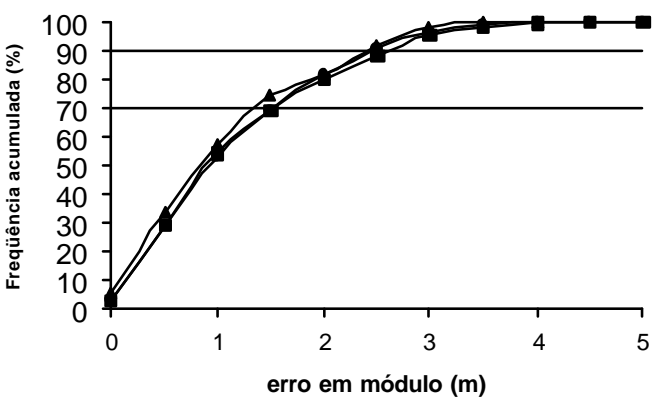

Junção da simulação 2 com a simulação 3

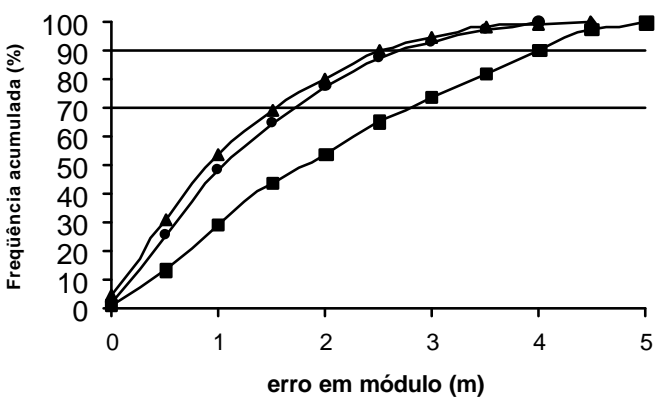

Junção da simulação 1 com a simulação 3

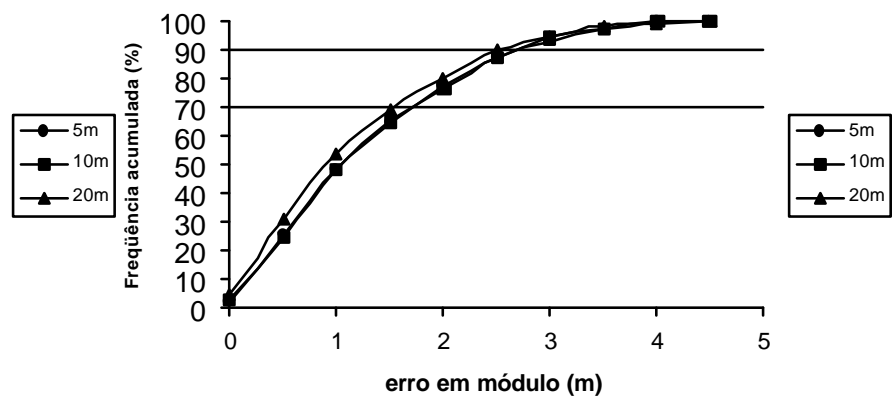

Junção das três simulações

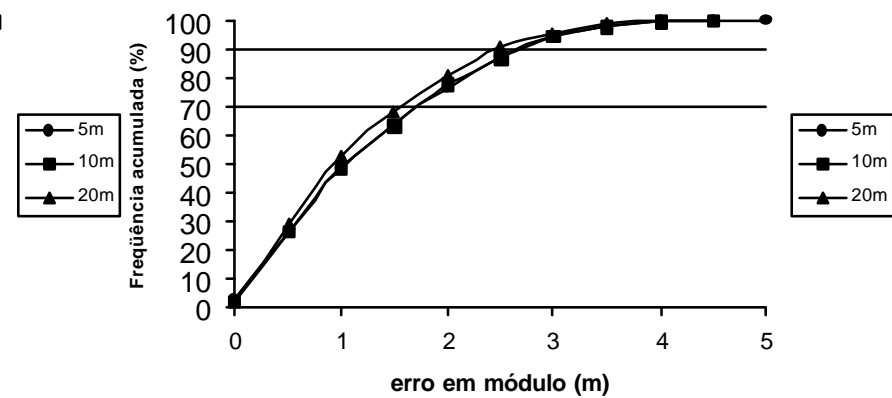

Figura 11 - Freqüências acumuladas das junções de dados das simulações de operação de colheita, pelo critério de comparação por células.

$\mathrm{Na}$ junção da primeira com a segunda simulação de colheitas, $70 \%$ dos dados estão com erro em módulo em torno de 1,5 m e 90\% dos dados, ao redor de 2,5 m. Na junção da primeira com a terceira simulação de colheita, $70 \%$ dos dados estão com erro em módulo em torno de $1,5 \mathrm{~m}$ e $90 \%$ dos dados, ao redor de 2,5 m. Na junção da segunda com a terceira, tem-se $1,8 \mathrm{~m}$ e 2,5 $\mathrm{m}$ de erro para $70 \%$ e $90 \%$ dos dados, respectivamente, e a junção das três simulações de colheita resultou em valores de erros de $1,5 \mathrm{~m}$ para $70 \%$ e $2,5 \mathrm{~m}$ para $90 \%$ de probabilidade. Observa-se que a junção de dados se mostrou favorável, melhorando a acurácia em relação aos conjuntos de dados isolados. 
Na Figura 12, são apresentadas as freqüências acumuladas dos erros em módulo, para os dados obtidos pela junção das simulações através do critério de comparação por raio de busca .

Junção da simulação 1 com a simulação 2

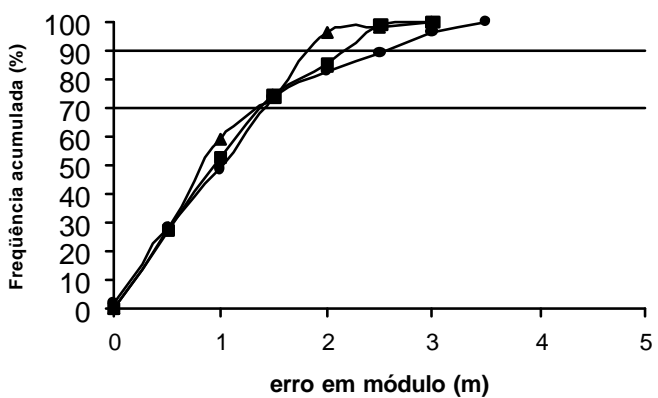

Junção da simulação 2 com a simulação 3

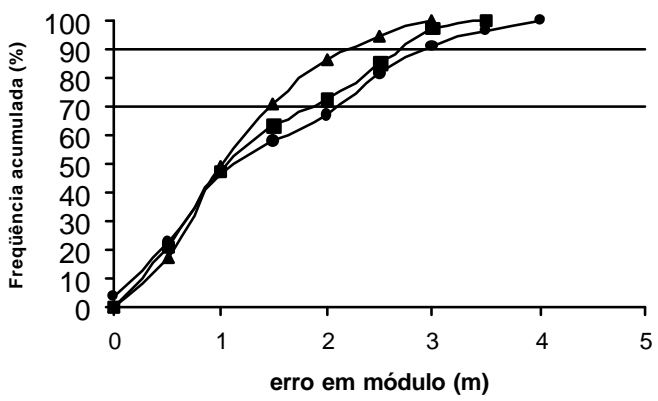

Junção da simulação 1 com a simulação 3

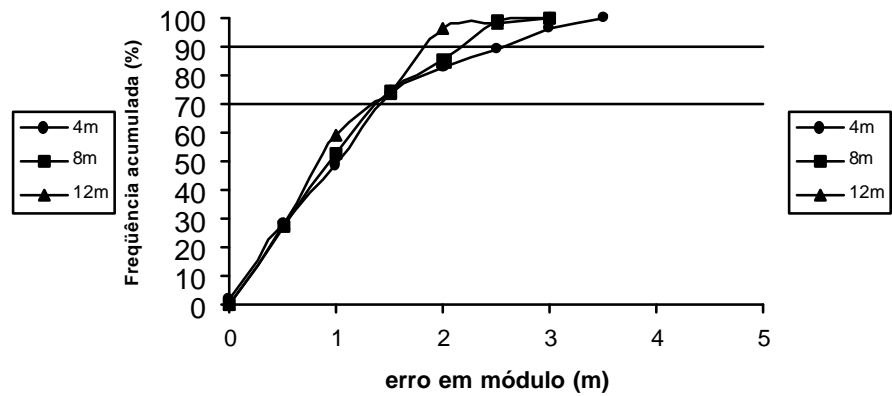

Junção das três simulações

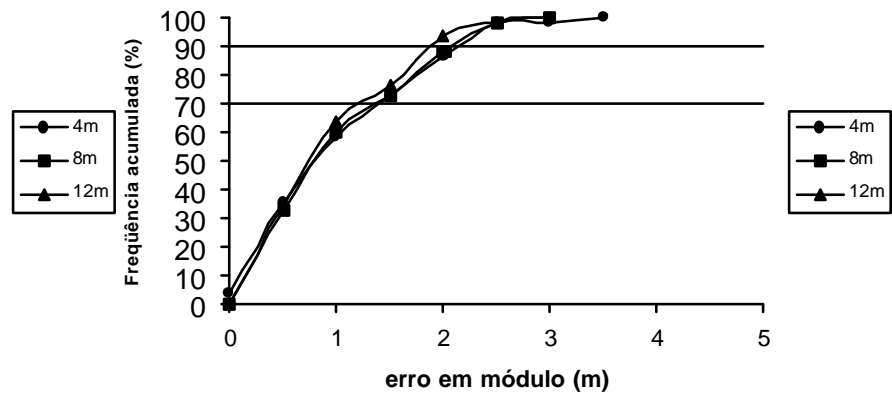

Figura 12 - Freqüências acumuladas dos erros em módulo, para os dados de altimetria, para as junções de dados das simulações de colheitas, critério de comparação por raio de busca. 
As junções dos dados das simulações de colheita melhoraram a qualidade da informação. Para a junção da primeira com a segunda simulação, $70 \%$ dos erros em módulo estão em torno de $1,5 \mathrm{~m}$ e $90 \%$ estão em torno de 2,5 m. Para a junção da primeira com a terceira simulação, ocorreu erro em modulo de $1,5 \mathrm{~m}$ para $70 \%$ dos dados e de $2,5 \mathrm{~m}$ para $90 \%$. Na junção da segunda com a terceira simulação, tem-se $1,8 \mathrm{~m}$ e 2,8 $\mathrm{m}$ para 70 e $90 \%$, dos dados, respectivamente, e para a junção das três simulações, temos o erro em módulo em torno de $1,5 \mathrm{~m}$ para $70 \%$ dos dados e de $2,2 \mathrm{~m}$ para $90 \%$.

A junção dos dados das simulações, com interpolação por raio de busca melhorou a qualidade da informação, aumentando em até $40 \%$ a acurácia em relação às simulações individuais. O erro máximo em módulo ficou em torno de $3,5 \mathrm{~m}$, com redução de $30 \%$ dos erros em relação às simulações originais.

Nas Figuras 13 e 14, a título de exemplo, são apresentados os modelos de elevação de terreno para a simulação de colheita 1 . 

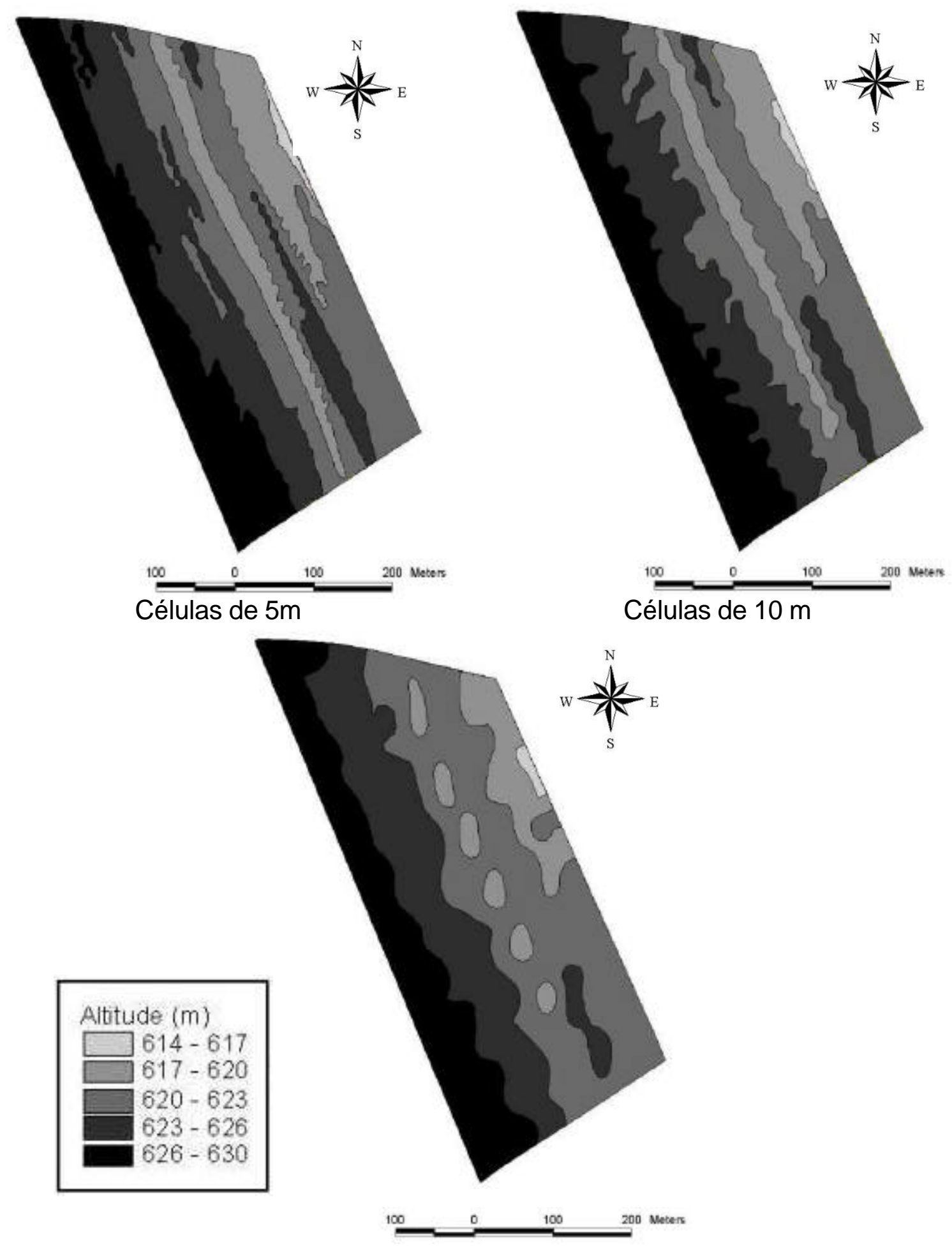

Células de $20 \mathrm{~m}$

Figura 13 - Reprodução do modelo de elevação do terreno, com dados da primeira simulação de colheita, pelo critério de comparação por células. 

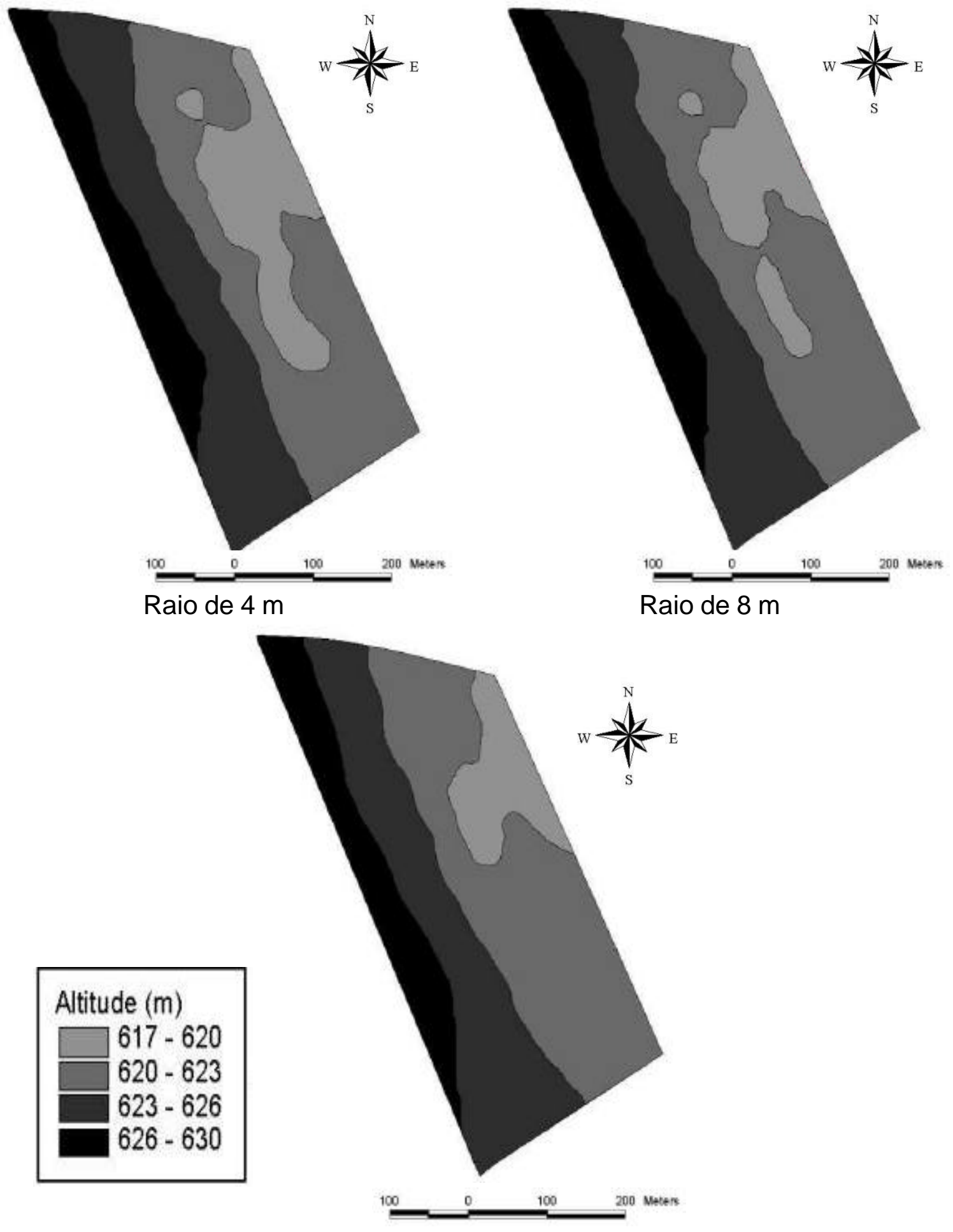

Raio de $12 \mathrm{~m}$

Figura 14 - Reprodução do modelo de elevação do terreno, com dados da primeira simulação de colheita, pelo critério de comparação por raio de busca. 
As representações gráficas do modelo de elevação do terreno, obtidas com a simulação de colheita e pelo critério de comparação por células (Figura 13), mantêm a mesma tendência em relação ao levantamento realizado de forma convencional, com a utilização de estação total (Figura 8). Os modelos de elevação obtidos apresentam o mesmo desnível, alterando a representação gráfica da transição das cotas, com a mesma tendência na perpendicular às curvas de nível para a declividade da área; porém, na direção longitudinal (sudeste-nordeste), há a representação da variação de cotas, o que não é observado no levantamento convencional.

Para os modelos de elevação gerados através do critério de comparação por raio de busca (Figura 14), o desnível encontrado é o mesmo em relação aos dados do levantamento convencional. Apresenta o mesmo comportamento da representação gráfica na perpendicular æ̀ curvas de nível, em relação ao modelo de elevação obtido de forma convencional, e com melhor fidelidade à representação das cotas no sentido longitudinal em relação ao método de interpolação por células.

\subsection{Acurácia de mapas altimétricos obtidos com monitor de produtividade}

$\mathrm{Na}$ Tabela 3, são apresentados os erros de altitude obtidos com os dados do monitoramento das colheitas 1 e 2 . 
Tabela 3. Resultados da análise estatística descritiva dos erros de altitude, obtidos através do monitoramento das colheitas 1 e 2, em relação aos dados do levantamento realizado pelo método convencional.

\begin{tabular}{|c|c|c|c|c|c|c|c|}
\hline \multirow[b]{2}{*}{ Colheita } & \multirow[b]{2}{*}{ Critério } & \multicolumn{6}{|c|}{ Erro de altitude } \\
\hline & & $\begin{array}{c}\text { Média } \\
(\mathrm{m})\end{array}$ & $\begin{array}{c}\text { Mediana } \\
(\mathrm{m})\end{array}$ & $\begin{array}{c}\text { Amplitude } \\
\text { (m) }\end{array}$ & $\begin{array}{c}\text { Valores } \\
\text { Negativos } \\
(\%)\end{array}$ & $\begin{array}{c}\text { Valores } \\
\text { Positivos } \\
(\%)\end{array}$ & $\begin{array}{c}\text { Valores } \\
\text { Nulos } \\
(\%)\end{array}$ \\
\hline 1 & Célula de 5m & 0,0 & $-1,7$ & 24,1 & 63,2 & 36,3 & 0,5 \\
\hline 1 & Célula de10m & 0,0 & $-0,9$ & 23,1 & 64,0 & 35,3 & 0,7 \\
\hline 1 & Célula de $20 \mathrm{~m}$ & 0,0 & $-0,6$ & 21,4 & 60,7 & 37,9 & 1,4 \\
\hline 1 & Raio de $4 \mathrm{~m}$ & $-0,7$ & $-0,9$ & 8,4 & 63,7 & 34,4 & 1,8 \\
\hline 1 & Raio de $8 \mathrm{~m}$ & $-0,6$ & $-0,4$ & 8,5 & 58,5 & 41,5 & 0,0 \\
\hline 1 & Raio de $12 \mathrm{~m}$ & $-0,5$ & $-0,3$ & 7,8 & 58,7 & 41,3 & 0,0 \\
\hline 2 & Célula de $5 \mathrm{~m}$ & 2,6 & 0,5 & 31,3 & 46,4 & 53,0 & 0,6 \\
\hline 2 & Célula de $10 \mathrm{~m}$ & 2,7 & 0,8 & 24,0 & 42,7 & 56,3 & 1,0 \\
\hline 2 & Célula de $20 \mathrm{~m}$ & 2,7 & 1,4 & 22,4 & 38,8 & 59,3 & 1,9 \\
\hline 2 & Raio de $4 \mathrm{~m}$ & 3.5 & 2.5 & 18,9 & 24,1 & 75,9 & 0,0 \\
\hline 2 & Raio de $8 \mathrm{~m}$ & 2,9 & 2,0 & 14,2 & 25,8 & 74,2 & 0,0 \\
\hline 2 & Raio de $12 \mathrm{~m}$ & 2,7 & 2,0 & 12,7 & 22,3 & 77,7 & 0,0 \\
\hline
\end{tabular}

A qualidade da informação, para as duas colheitas, é bem distinta. Os dados obtidos na colheita 1 apresentam predomínio de valores de erros negativos, enquanto, para os dados provenientes da colheita 2, é observado o predomínio de erros positivos, gerando, assim, a tendência de subestimar os valores de altitude com os dados provenientes da colheita 1, e superestimar as cotas com dados da colheita 2. Há grande amplitude nos dois conjuntos de dados. Para o conjunto de dados obtidos na colheita 1 e analisados pelo critério de comparação por raio, observa-se que é menor quase duas vezes em relação ao critério de comparação por células, o mesmo ocorrendo para o conjunto de dados da colheita 2, quase uma vez menor. Observa-se que há uma tendência 
de diminuição da amplitude, quando se utilizam tamanhos de células e raios maiores para se efetuar a comparação.

Nas Figuras 15 e 16, vê-se a representação gráfica das freqüências acumuladas dos erros em módulo, dos dados provenientes do monitor de produtividade, obtido em colheitas realizadas na mesma área onde foram realizadas as simulações com resultados apresentados no item 4.2, em relação ao levantamento realizado de forma convencional. A colheita 1 foi realizada em julho de 2001 e a colheita 2, em abril de 2002. 


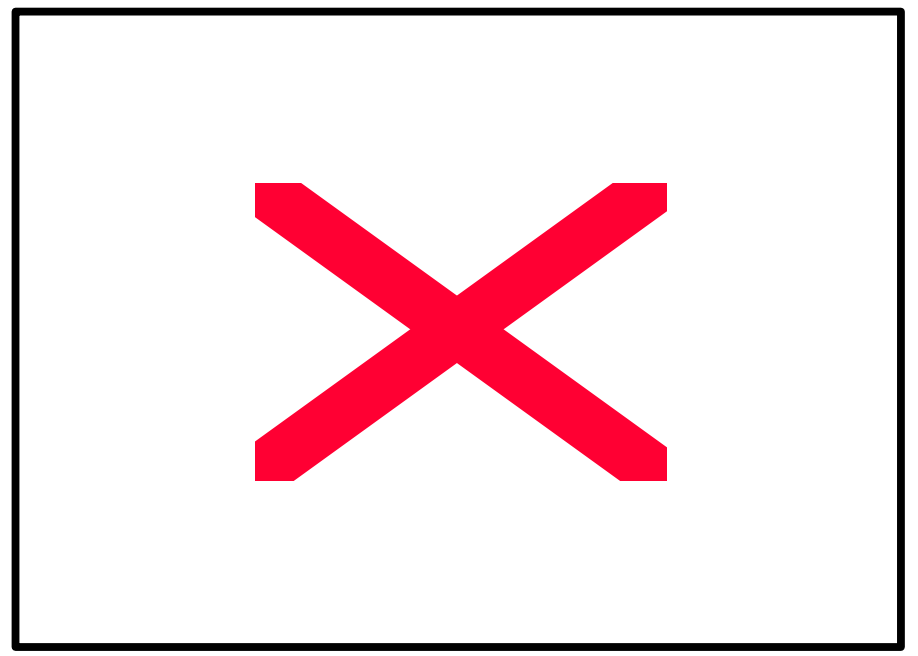

Collheita 2

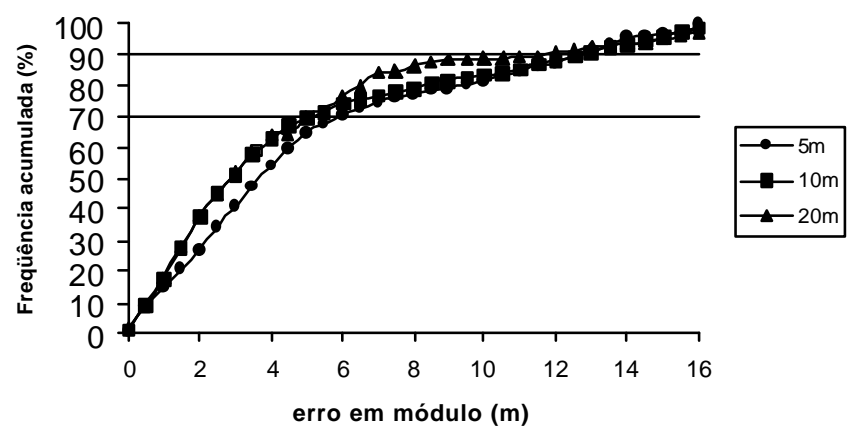

Figura 15 -Representação gráfica da freqüência acumulada dos erros, obtidos pelo critério de comparação por células, com dados provenientes de monitor de produtividade. 
Collheita 1

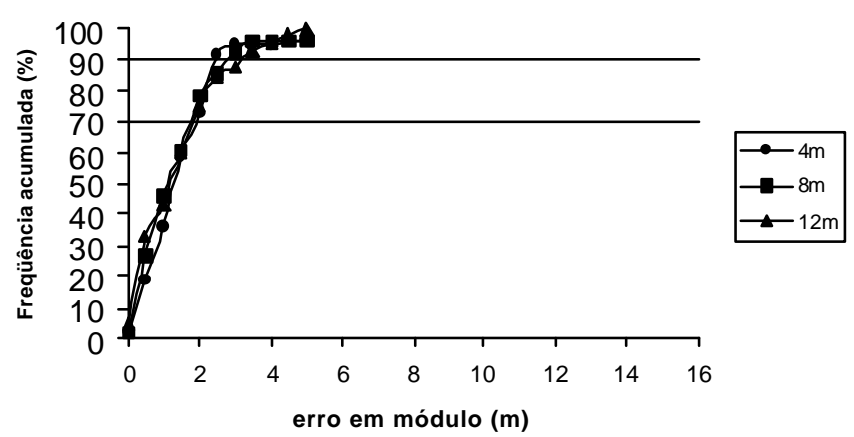

Collheita 2
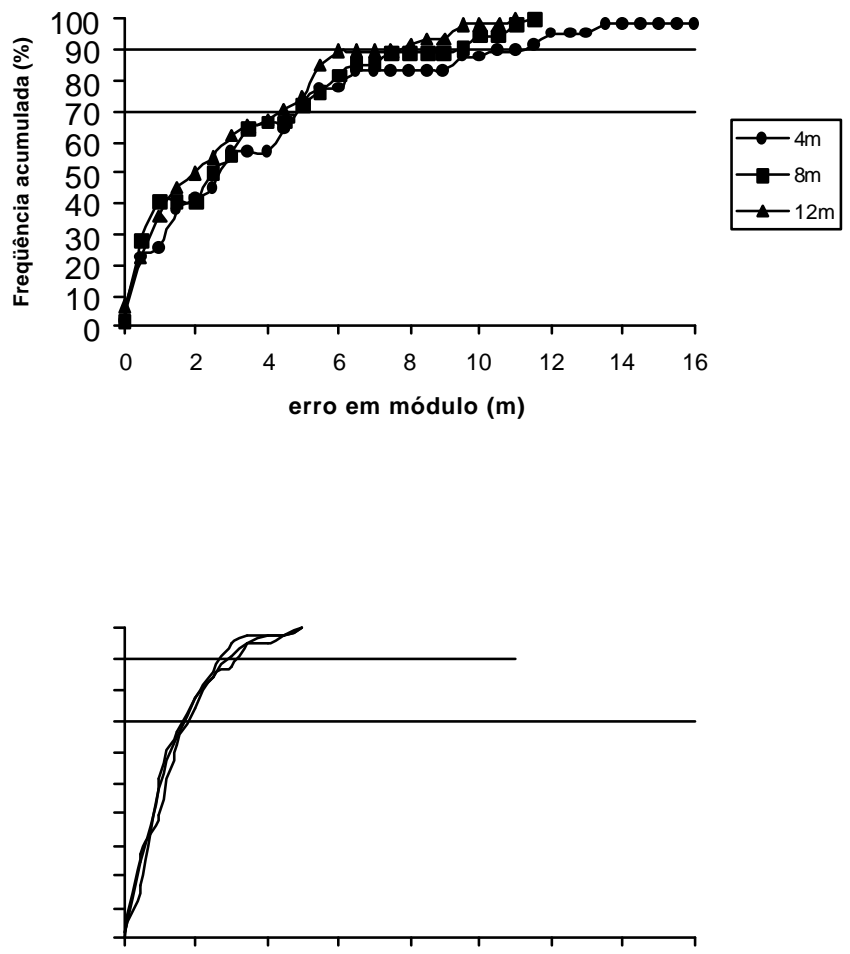

Figura 16 - Representação gráfica da freqüência acumulada dos erros, obtidos pelo critério de comparação por raio de busca, com dados provenientes de monitor de produtividade. 
$\mathrm{Na}$ Figura 15, representa-se a freqüência acumulada dos erros em módulo, provenientes do monitoramento da colheita 1. Entre eles, $70 \%$ estão em torno de 4,0 m e $90 \%$, próximos a $8,0 \mathrm{~m}$. Para os dados provenientes da colheita 2, 70\% estão ao redor de 5,0 m e 90\%, em torno de 12,0 m. Na junção dos dados das duas colheitas, os erros estão ao redor de $4,0 \mathrm{~m}$, para $70 \%$ dos dados, e próximos de $8,0 \mathrm{~m}$, para $90 \%$ dos dados. A junção de dados não melhorou a qualidade da informação, mantendo os mesmos níveis de acurácia em relação aos dados provenientes da colheita 1, não tendo a influência dos resultados da colheita 2.

$\mathrm{Na}$ Figura 16, apresentam-se as freqüências acumuladas dos erros obtidos através do raio de busca, para os dados provenientes do monitoramento da colheita 1. Para $70 \%$ dos dados, os erros em módulo estão próximos de $2,0 \mathrm{~m}$ e, para $90 \%$ dos dados, os erros em módulo estão em torno de $3,5 \mathrm{~m}$. Para os dados do monitoramento da colheita 2, 70\% estão ao redor de $4,5 \mathrm{~m}$ e $90 \%$, próximos de 7,0 m. Para a junção dos dados, os níveis de acurácia são os mesmos encontrados no monitoramento da colheita 1 e na ordem de $2,0 \mathrm{~m}$ para $70 \%$ dos dados e de $3,5 \mathrm{~m}$ para $90 \%$ deles.

Observando-se a tabela 3, percebe-se que $60 \%$ dos dados provenientes da colheita 1 são erros com valores negativos; já $55 \%$ dos dados provenientes da colheita 2 são erros com valores positivos, obtidos pelo critério de comparação por células. Pelo critério de comparação por raio de busca, 75\% dos erros possuem valores positivos. Os dados da colheita 1 apresentam amplitude média de 22,8 m, pelo critério de comparação por células; já pelo critério de comparação por raio de busca, a amplitude média é de 8,2 m. Para a colheita 2 os dados apresentam amplitude média de 25,9 m, pelo critério de comparação por células; já pelo critério de comparação por raio de busca, a amplitude média é de 15,2 m. 
Os dados obtidos pelo critério de comparação por raio de busca apresentaram maior acurácia, em relação aos dados obtidos pelo critério de comparação por células.

Na Figura 17 apresenta-se o modelo de elevação do terreno obtido com dados provenientes do monitoramento da colheita 1. 

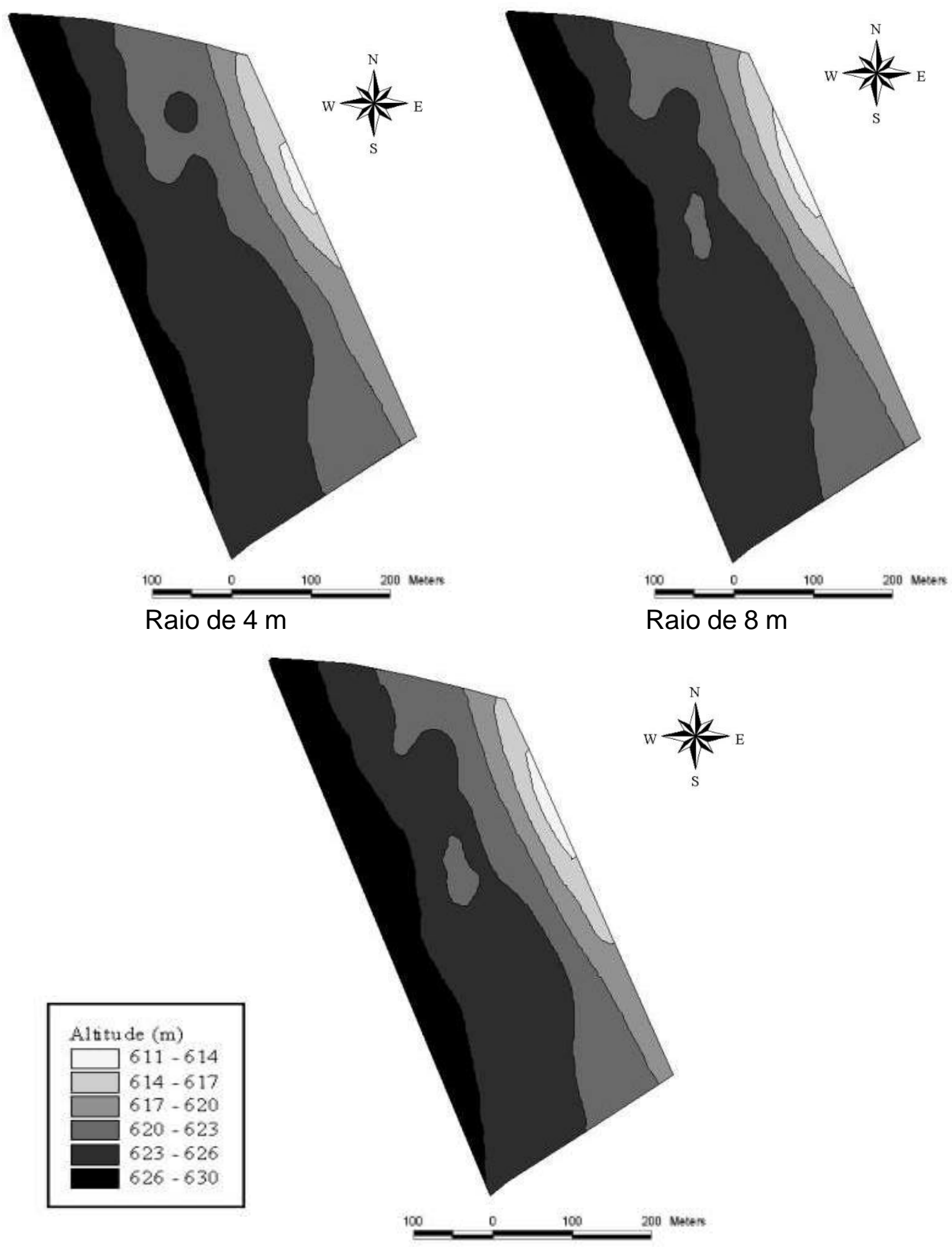

Raio de $12 \mathrm{~m}$

Figura 17 - Reprodução de modelos de elevação do terreno, a partir dados do monitoramento da colheita 1 , com erros obtidos pelo critério de comparação por raio de busca. 
Nos modelos de elevação do terreno da Figura 17, a declividade encontrada fica em torno de $10 \%$, superestimando o valor de $6,8 \%$, obtido pelo levantamento realizado de forma convencional. As faixas de transição de cotas na transversal apresentam a mesma tendência em relação aos valores encontrados no modelo de elevação do terreno, obtido de forma convencional, porém com maior amplitude dos valores das cotas. Os valores dos erros, na sua maioria, são negativos, influenciando a acurácia dos mapas e gerando a subestimativa em relação ao desnível e a maior amplitude das cotas, em relação ao modelo de elevação obtido de forma convencional.

\subsection{Considerações gerais}

Os métodos convencionais de obtenção de dados de altimetria, como levantamento através de estação total, ortofotos e outros, são trabalhosos e dispendiosos, porém apresentam boa acurácia. Perante a disponibilidade da obtenção de dados de altimetria, como um produto secundário, em operações agrícolas que se utilizem de receptores de GPS, seja da colheita com mapeamento da produtividade de grãos, seja do tráfego de máquinas em operações agrícolas que utilizam receptor de GPS para navegação, seja ainda de pulverizações e aplicações de corretivos e fertilizantes ou mapeamento da condutividade elétrica do solo, é importante conhecer-se a acurácia dos dados.

A acurácia de dados obtidos com receptores de GPS, utilizados em Agricultura de Precisão, é muito variável pois, a qualidade da informação está ligada ao arranjamento dos satélites visados, no momento da obtenção dos dados. A incerteza da qualidade obtida pode ser minimizada com a coleção de alguns conjuntos de dados em uma mesma área. A junção dos conjuntos de dados das simulações neste trabalho melhorou a qualidade da informação, 
porém a junção dos dois conjuntos de dados, oriundos das colheitas, não chegou a melhorar a informação. No entanto não prejudicou a qualidade em relação aos dados originais e individuais.

Os dados de altimetria obtidos neste trabalho têm acurácia mínima para gerar, como produto, mapa de elevação do terreno. Com essa informação, é possível conhecer o relevo local, constatar classes de declividade, desnível do terreno e identificar áreas em um mesmo talhão que possam ser priorizadas para melhor entendimento da variabilidade na produção agrícola. Porém isso só é válido em regiões de relevo acidentado. Em relevos mais planos o sistema não oferece a acurácia necessária.

A informação aqui obtida tem um custo baixo, em comparação a produtos oriundos do levantamento convencional, o que caracteriza uma importante vantagem.

As técnicas de Agricultura de Precisão visam à melhoria do gerenciamento da produção agrícola; portanto informações de altimetria obtidas com monitores de produtividade podem incrementar as tomadas de decisões gerenciais, na busca da melhor compreensão dos fatores que influenciam direta ou indiretamente a produtividade. Esse tipo de informação pode ser aplicado no dimensionamento e no planejamento de amostragens de solo, na definição de unidades de gerenciamento diferenciado e em outras atividades. 


\section{CONCLUSÕES}

No levantamento dos perfis, os dados obtidos com receptor de GPS, com correção de sinal pós-processada, mostraram-se mais acurados do que os dados obtidos com receptor de GPS com correção de sinal via satélite.

As interpolações feitas, utilizando-se diferentes tamanhos de células, não interferiram na qualidade da informação. Os dados obtidos pelo critério de comparação por raio de busca, com o maior raio testado (12 m), resultaram em melhor qualidade da informação. Já a junção dos dados das simulações, de maneira geral, melhorou a qualidade da informação.

Os dois conjuntos de dados provenientes do monitor de produtividade apresentam acurácias distintas, com melhor resultado para o conjunto de dados obtido na colheita 1. O critério de comparação por raio de busca fornece dados com melhor acurácia que os obtidos pelo critério de comparação por células. Já a junção dos dados das duas colheitas não melhorou a qualidade da informação.

Os dados obtidos possuem acurácia para subsidiar estudos com variáveis relacionadas à altimetria, em áreas com relevo acidentado, não possuindo qualidade para subsidiar intervenções que requeiram precisão, como é o caso de relevos planos. 


\section{Referências Bibliográficas}

AVELLAR, G., FRANÇA, G. E., OLIVEIRA, AA. C., MANTOVANI, E.C., Uso de SIG'S no delineamento de zonas de manejo para uso agrícola. (compact disc) In: SIMPÓSIO INTERNACIONAL DE AGRICULTURA DE PRECISÃO. 2.,Viçosa, 2002, Anais. Viçosa: 2002.

BAIO, F.H.R; ÂNGULO FILHO, R.; VETTORAZZI, C.A.; RAFFO, J.G.G.; ELIAS, A. I. Estudo da exatidão de um GPS operando em duas taxas de aquisição de dados. In: CONGRESSO BRASILEIRO DE ENGENHARIA AGRÍCOLA, 27., Poços de Caldas, 1998. Anais. Jaboticabal: SBEA, 1998. p.347-349.

BAIO, F.H.R.; RAFFO, J.G.; ANGULO FILHO. R.; VETTORAZZI, C. A.; DEMÉTRIO, V. Acuracidade de equipamentos GPS de navegação e sua possível aplicabilidade em trabalhos topográficos. In: CONGRESSO BRASILEIRO DE ENGENHARIA AGRÍCOLA, 27., Poços de Caldas, 1998. Anais. Jaboticabal: SBEA, 1998, p. 436-437.

BAKHSH. A.; $\subset$ LVIN, T.S.; JAYNES, D.B.; KANWAR, R.S.; TIM, U.S. Using soil atributes and GIS for Interpretation of Spatial Variability in Yield. Transactions of the ASAE, v. 43, n.4, p.819-828, 2000. 
BALASTREIRE, L. A.; BAIO, F.H.R. Avaliação da acurácia de um GPS com algoritmo otimizado sem sinal de correção para agricultura de precisão DGPS. (compact disc) In: BALASTREIRE, L. A Avanços na Agricultura de Precisão no Brasil de 1999-2001, Piracicaba, p.287-289, 2002.

BALASTREIRE, L. A., BAIO, F.H.R., AMARAL, J.R., RODRIGUES, A. A. Avaliação da acurácia cinemática de um sistema de posicionamento global diferencial, utilizando na Agricultura de Precisão. (compact disc) In: BALASTREIRE, L.A. O estado da arte da Agricultura de Precisão no Brasil, Piracicaba, p. 173-181, 2000.

BLITZKOW, D. Aspectos gerais do sistema NAVSTAR/GPS. São Paulo: EDUSP, 1995. $31 \mathrm{p}$.

BUCENE, L.C.; RODRIGUES, J. B. T.; VETTORATO, J.A.; ZIMBACK, C.R.L. Análise espacial e interpolação por krigagem em dados de altimetria (compact disc) In: CONGRESSO BRASILEIRO DE ENGENHARIA AGRíCOLA, 30., Foz do Iguaçu, Paraná, 2001. CONBEA 2001. Foz do Iguaçu: SBEA:2001.

BUICK, R.D.; CALLAGHAN, O. M. Precision agriculture: an integration of information technologies with farming. In: NEW ZEALAND PLANT PROTECTION CONFERENCE, 5., Canterbury, Proceedings, 1997, p. 176184.

CLARK, R. L. A comparison rapid GPS techniques for topographic mapping. In: INTERNATIONAL CONFERENCE ON PRECISION AGRICULTURE, 3., Minneapolis, 1996. Proceedings. Madison: ASA,CSSA,SSSA, 1996, p.651662. 
CLARK, R.L.; LEE, R. Development of topographic maps for precision farming with kinematic GPS. Minneapolis, ASAE:,1997. (ASAE Paper, 971035).

ESQUERDO, J.C.D.M. Adaptação de um pulverizador convencional para a aplicação localizada de defensivos agrícolas. Piracicaba, 2002. 98p. Dissertação (Mestrado) - Escola Superior de Agricultura "Luiz.de Queiroz", Universidade de São Paulo.

FRAISSE, C.W.; SUDDUTH, K.AA.; KITCHEN, N.R. Delineation of site-specific management zones by unsupervised classification of topography attributes and soil electrical conductivity. Transactions of the ASAE, n. 44, p. 155166, 2001.

FRANZEN, D.W.; HALVORSON, A.D.; HOFMAN, V. L. Management zones for Soil $\mathrm{N}$ and $\mathrm{P}$ levels in the Northern Great Plains. (compact disc). In: INTERNATIONAL CONFERENCE ON PRECISION AGRICULTURE, 5., Madison, 2000. Proceedings. Madison: ASA, 2000. p. 63.

FRIDGEN, J. J.; KITCHEN N.R.; SUDDUTH, K.A. Variability of soil and Landscape Attributes Within Sub-Field Management Zones. (compact disc). In: INTERNATIONAL CONFERENCE ON PRECISION AGRICULTURE, 5., Madison, 2000. Proceedings. Madison: ASA, 2000. p. 128.

HAN, S.; RAWLINS, S.L.; SCHNEIDER, S.M.; EVANS, R.G. Yield mapping with differential GPS, St. Joseph: ASAE, 1995, 6p. (ASAE Paper, PNW95-302). 
HOFMANN-WELLWNHOF, B.; LICHTENEGGER, H.; COLLINS, J. Global Position System, Theory and Practice. Viena, Springer-Verlag Wien, 1992, $325 \mathrm{p}$.

HOLLANDS, K. R. Relationship of Nitrogen and Topography. In: INTERNATIONAL CONFERENCE ON PRECESION AGRICULTURE, 3., Minneapolis, 1996. Proceedings. Madison: ASA,CSSA,SSSA, 1996, p. 412.

IRMACK, A. A. JONES, J.W.; BATCHELOR W.D.; PAZ, J.O. Estimating spatially variable soil propreties for application of crop models in precision farming. Transactions of the ASAE, v.44, n. 5, p.1343-1353, 2001.

JOHANSEN, D.P.; CLAY, D. E.; CARLSON, C.G.; STANGE, K.W.; CLAY, S. A. A.; MALO, D. D.; SCUMACHER, J. A.A. Vertical accuracy of two differentially correct global positiong satellite systems. Journal of Soil and Water Conservation. v. 53, n. 3, 2001. p. 198-201.

JOHNSON, G. A.; BICKELL, M. D.. Using DGPS and GIS for knowledge-Based Precision Agriculture Applications. In: INTERNATIONAL CONFERENCE ON PRECESION AGRICULTURE, 3., Minneapolis, 1996. Proceedings. Madison: ASA,CSSA,SSSA, 1996. p.328-332.

KRAVCHENKO, A. N.; BULLOCK, D.G. Correlation for corn and soybean grain yield with topography and soil properties. Agronomy Journal, v.1, n. 92, p.75-83, 2000. 
KRAVCHENKO, A. N.; BULLOCK, D.G.; REETZ, H.F. Spatial variability of grain yield as function of topography and soil properties. In: EUROPEAN CONFERENCE ON PRECISION AGRICULTURE '99, 2., Odense, 1999. Proceedings. London: Sheffield Academic Press, 1999. p. 441-450.

KRAVCHENKO, A. N.; BULLOCK, D.G.; BOAST, C.W. Joint multifractal analysis of crop yield and terrain slope. Agronomy Journal, v.4, n.3, p.1279- 1290, 2000.

KRUMMEL, J.; SU, H. Topographic Effect and Its Relation to Crop Production. In: INTERNATIONAL CONFERENCE ON PRECISION AGRICULTURE, 3., Minneapolis, 1996. Proceedings. Madison: ASA,CSSA,SSSA, 1996, p.651662.

KUTCHER, H. R.; MALHI, S.S.; JOHNSTON, A. M.; HNATOWICH, G. Impact of Topography and Management on Diseases of Canola and Wheat. In: INTERNATIONAL CONFERENCE ON PRECISION AGRICULTURE, 4., Proceedings. Ontario, 1999, p.559-561.

LAMPARELLI, R. A. C.; ROCHA, J. V.; BORGHI, E. Geoprocessamento e Agricultura de Precisão. Guaíba: Editora Agropecuária, 2001. 118 p.

LECHNER, W.; BAUMANN, S. Global navigations satellites systems. Computers and Eletronics in Agriculture, v.25, p.67-85, 2000.

LOGSDON, T. The Navstar Global Positioning System. New York, Van Nostrand Reinhold, 1992, 256 p. 
MACK, G. Precise positioning for agriculture. In: EUROPEAN CONFERENCE ON PRECISION AGRICULTURE '97, 1., Warwick, 1997. Proceedings. London: BIOS Scientific, 1997. p.593-602.

MENEGATTI, L. A. A. Metodologia para identificação, caracterização e remoção de erros em mapas de produtividade. Piracicaba, 2002. 84p. Dissertação (Mestrado) - Escola Superior de Agricultura "Luiz.de Queiroz", Universidade de São Paulo.

MOLIN, J.P. Agricultura de precisão: $O$ gerenciamento da variabilidade. Piracicaba: Tipografia Piracicabana, 2001. 81p.

MOLIN, J.P. Utilização de GPS em Agricultura de precisão. Engenharia Agrícola, v.17, n.3, p. 121-132, 1998.

MOLIN, J.P. Geração e interpretação de mapas de produtividade para agricultura de precisão, In: BORÉM, A.; GIÚDICE, M.P. Del; QUEIROZ, D.M de; MANTOVANI, E.C.; FERREIRA, L.R.; VALLE, F.X.R. DO; GOMIDE, R.L. Agricultura de Precisão. Viçosa: Universidade Federal de Viçosa, 2000. p. 237-258.

MOLIN, J.P.; RUIZ, E.R.S. Accuracy of DGPS for ground application in parallel swaths. St. Joseph: (ASAE Paper, 991043), 1999.

MORAES, J.F.L.; NEGREIROS, S.R.; VIEIRA, MARTINHO, P. Digital Elevation Modeling and relief attributes obtained through DGPS survey and Interpolation analysis. (compact disc). In: EUROPEAN CONFERENCE ON PRECISION AGRICULTURE, 3, Proceedings, Montpellier,2001. 6 p. 
MORGAN, M., ESS, D. The precision farming guide for agricultorists. Moline: Derre, 1997. 117 p.

NUGTEREN, A. A.; ROBERT, P. C. Usefulness and feasibility of high accuracy digital elevation models for precision management. www.ppifar.org (24 Out. 2001).

NUGTEREN, T.; ROBERT, P.C.. Corn Grain Quality as Afected by soil properties, management and landscape, (compact disc). In: INTERNATIONAL CONFERENCE ON PRECISION AGRICULTURE, 5., Madison, 2000. Proceedings. Madison: ASA, 2000. p.27.

OSTP Statement by the President regarding the United States' decision to stop degrading Global Positioning System accuracy, www.ostp.gov, (28 Out 2001).

PENNOCK, D. J.; WALLEY, F. L.; SOLOHUB, M. P.; HNATOWICH, G. Yield Response of Wheat and Canola to a topographically Based Variable Rate Fertilization program in Saskatchewan, In: INTERNATIONAL CONFERENCE ON PRECIOSION AGRICUTURE, 5., Minneapolis, 1999. Proceedings. Madison: ASA, CSSA, SSSA, 1999. p. 797-805.

ROBERT, P.C. The economical feasibility of precision agriculture. (compact disc) In: SIMPÓSIO INTERNACIONAL DE AGRICULTURA DE PRECISÃO. 2.,Viçosa, 2002, Anais. Viçosa: 2002. 
SANTOS, A. O.; MAZIERO, J.V.G.; CAVALLI, A. C.; VALERIANO, M.M.; de OLIVEIRA, H.; MORAES, J.F.L.; YANAI, K. Monitoramento localizado da produtividade de milho cultivado sob irrigação. Revista Brasileira de Engenharia Agrícola e Ambiental, v.5, n.1, p.88-95, 2001.

STAFFORD, J.V.; AMBLER, B. In-field location using GPS spatially variable field operations. Computers and Eletronics in Agriculture, v.11, p.2336,1994 .

SUDDUTH, K. A.; DRUMMOND, S. T.; BIRRELL, S. J.; KITCHEN, N. R. Spatial Modeling of crop yield using soil and topographic data, In: EUROPEAN CONFERENCE ON PRECISION AGRICULTURE, 1., Warwick, 1997. Precision Agriculture'97. Warwick: BIOS Scientific, 1997. p.439-447.

THE FEDERAL AVIATION ADMINISTRATION, www.faa.gov, (15 Abr.2002).

VERMA, A. K.; COOKE, R. A.; TIAN, L.F.; HIRSCHI, M. C.; MITCHELL, J.K. Using GIS and GPS for variable rate application (VRA) of agri-chemicals. Orlando: ASAE, 1998. (ASAE Paper, 983136).

VIEIRA, S.R. Geoestatística aplicada à agricultura de precisão. In; BORÉM, A.; GIÚDICE, M.P. Del; QUEIROZ, D.M de; MANTOVANI, E.C.; FERREIRA, L.R.; VALLE, F.X.R. DO; GOMIDE, R.L. Agricultura de Precisão. Viçosa: Universidade Federal de Viçosa, 2001. p. 117-125.

WALLEY F.; PENNOCK, D.; SOLOHUB, M.; HNATOWICH, G. Spring wheat yield and grain protein responses to $\mathrm{N}$ fertilizaer in topographically. Canadian Journal of Soil Science, v.81, n. 3, p. 505-514, 2001. 
YANG, C.; PETERSON, C.L.; SHROPSHIRE, G.J.; OTAWA, T. Spatial variability of field topography and wheat yield in the Palouse region of the Pacific Northwest. Transactions of the ASAE, v. 41, n.1, p. 17-28, 1998.

YAO, H. B., CLARK, R. L. Development of topographic maps for precision farming with sub-meter horizontal accuracy GPS receiver. Toronto: ASAE, 1999. (ASAE Paper 993108).

YAO, H. B.; CLARK, R.L. Development of topographic maps for precision farming with medium accuracy GPS receiver. Applied Engineering in Agriculture, v.16, n.6, p. 629-636, 2000. 